\title{
ANALYTICAL BOND MODEL FOR GFRP BARS TO STEEL FIBER REINFORCED SELF-COMPACTING CONCRETE
}

\author{
By H. Mazaheripour, ${ }^{1}$ J. A. O. Barros, ${ }^{2}$ J. Sena-Cruz, ${ }^{3}$ F. Soltanzadeh, ${ }^{4}$
}

\begin{abstract}
The objective of this study is to present a computational algorithm to analytically evaluate the bond behavior between GFRP bar and steel fiber reinforced self-compacting concrete (SFRSCC). The type of information to be derived is appropriate to study the flexural behavior of SFRSCC beams reinforced with GFRP bars in terms of serviceability limit states requirements; in fact the bond between bars and surrounding concrete influences significantly the crack width and crack spacing. The proposed bond model was established by calibrating the parameters of a multilinear bond-slip constitutive law using the experimental results of pullout bending tests carried out by the authors, taking into account the experimental pullout force versus slip at loaded and free ends. According to the comparison between theoretical and experimental pullout force-slip, an acceptable accuracy of the model was observed. Additionally, by considering the proposed bond-slip relationship, a parametric study was carried out to evaluate the influence of the involved bond-slip law's parameters on the maximum force transferred to the surrounding concrete. Finally, the development length of two GFRP bars utilized in the experiments (deformed and smooth bars) was determined by means of the proposed model, and it was compared with the values recommended by codes.
\end{abstract}

Keywords: GFRP bars, FRC, bond model, pullout bending test

\footnotetext{
${ }^{1}$ ISISE, PhD student of the Structural Division of the Dep. of Civil Engineering, University of Minho, 4800-058 Guimarães, Portugal.hmp@civil.uminho.pt

${ }^{2}$ ISISE, Full Professor of the Structural Division of the Dep. of Civil Engineering, University of Minho, 4800-058 Guimarães, Portugal.barros@ civil.uminho.pt

${ }^{3}$ ISISE, Associate Professor of the Structural Division of the Dep. of Civil Engineering, University of Minho, 4800-058 Guimarães, Portugal. jsena@ civil.uminho.pt

${ }^{4}$ ISISE, PhD student of the Structural Division of the Dep. of Civil Engineering, University of Minho, 4800-058

Guimarães, Portugal. f.soltanzadeh@ civil.uminho.pt
} 


\section{Introduction}

The use of GFRP bars in the construction industry as an alternative reinforcement for concrete structures has increased continuously in the last two decades. Non-conductivity, high strength-to-weight ratio and the superior performance in corrosive environments (e.g. coastline structures) are the most advantages of GFRP bars. However, the relatively low Young's modulus and the lack of yielding phase in stress-strain respond introduce extra challenges in the flexural behavior of concrete members reinforced with GFRP bars, mainly in terms of accomplishing the requirements for serviceability limit states (Gravina and Smith, 2008; Barris et al., 2009). On the other hand, the bond performance of GFRP bars is inferior to steel bars (Choi et al., 2012; Harajli and Abouniaji, 2010). Hence, the serviceability limit states, such as controlling crack width and crack spacing, play a major role in designing GFRP RC structures.

Many attempts have been made to evaluate the bond behavior between GFRP bars and concrete, considering different parameters, e.g. the concrete compressive strength, bar diameter, surface treatment of bar, bar position in cross section of structural element, bond length, temperature change and etc. (Pecce et al., 2001, Tastani et al., 2006, Tang et al., 2008; Baena et al., 2009 and Masoudi et al., 2011). Among these, surface treatment of GFRP bar has been reported as one mostly affects the global bond behavior (He and Tian 2011; Harajli and Abouniaji 2010). Therefore, various surface treatment techniques (e.g. sand-coated, indented, ribbed, helical or wrapping) would provide different interfacial bond behavior. On the other hand, the bond between GFRP bar and concrete is a result of different three bond actions over the interface: chemical cohesion, friction and mechanical interlocking. The chemical bond between GFRP and concrete may be negligible when compared with the other two contributions. In fact, mechanical interlocking (specifically for deformed bar) and friction are dominant bond mechanisms, with an influence level on the bond performance that is dependent on the characteristic of the bar's surface. Theoretically, the bond behavior of GFRP bars is usually presented by a relationship between shear bond stress $(\tau)$ and the relative displacement between bar and concrete (i.e. slip). This bond-slip constitutive law is empirically presented by ascending and descending branches, which simulate the bond behavior of the bar before and after peak pullout load, respectively.

The first bond-slip relationship for GFRP bars was presented by Malvar in 1995. Later on, Cosenza et al. (1997) adopted for FRP bars the bond-slip constitutive law proposed by Eligehausen et al. (1983) for steel bars. This model is known as "double branch" and named mBEP (modified Bertero-Eligehausen-Popov). Furthermore, Cosenza et al. (1997) proposed a model with the designation of CMR (Cosenza-Manfredi-Realfonzo) that included a new ascending branch. All these bond-slip constitutive laws, and also other subsequent models (e.g. Zhang et al., 2000; Li et al., 2010) were based on equations that consider the peak bond stress and its corresponding slip derived from pullout force-slip relationships in pullout tests with specific type of bar and surface. Due to the variety of surface characterizations found in available FRP bars, higher difficulties are faced to propose standard constitutive law for the FRP-concrete bond behavior. He and Tian (2011) made an attempt, from the probabilistic standpoint (a database was collected for this purpose), to determine bond 
strength of GFRP bars based on reliability analysis. Despite of their efforts to suggest a factor to define the development length of GFRP bars, the analysis does not give idea about the distribution of bond stress and slip throughout the bond length, which is fundamental data for theoretical study on cracking behavior of GFRP RC structures. The database developed by these authors, however, only consider helically wrapped and spirally winded straight GFRP bars, which is very limited since other types of surface such as sand-coated or ribbed GFRP bars are nowadays quite current. Focacci et al. (2000) also defined a rigorous numerical method to calibrate the parameters of a given bond-slip law (they used CMR and mEBP models as example). Firstly, their method still depends on experimental results for calibration; secondly, according to their observations, in the most cases the contact surface between the FRP bar and concrete was highly irregular in consequent of the shape of the bar's surface.

In the light of the above explanation, the correct evaluation of the bond behavior of GFRP bars (FRP in general) still requires experimental verification in order to determine the bond-slip law's parameters for specific bars and surface. This has an extra motivation since GFRP bars are bonded to Steel Fiber Reinforced Self-Compacting Concrete (SFRSCC), forming an innovative composite system.

The present study is part of a research project with the purpose of developing High Performance Steel Fiber Reinforced Self-Compacting Concrete (HPSFRSCC) beams flexurally reinforced by hybrid pre-stressed GFRP and steel bars. GFRP bars are mounted at the bottom tensile surface of the beam while the pre-stressed steel bars are placed with higher concrete cover thickness in order to be protected against corrosive aspects. In this paper, a bond analytical formulation is presented by adopting a multi-linear bond-slip relationship $(\tau-\delta)$ for two types of GFRP bar's surface (ribbed and sand-coated) embedded in SFRSCC. To calibrate the $\tau-\delta$ and to appraise the analytical formulation, an extensive experimental program composed of pullout bending test was carried out by the authors. This experimental program was conceived in order to assess the influence of following parameters on the bond behavior: GFRP bar diameter, bar's surface treatment, bond length and SFRSCC cover thickness (Mazaheripour et al., 2012a). Additionally, a parametric study was carried out with the analytical formulation in order to evaluate the influence of involved bond-slip law's parameters on the maximum theoretical force that can be transferred to the surrounding SFRSCC through the bond length. Finally, the minimum theoretical bond length required to achieve the tensile strength of the GFRP bars was determined, and the obtained values are compared with those recommended by some published codes.

\section{Analytical Bond Model}

\section{Governing Equation}

Neglecting the deformability of surrounding concrete, and assuming a linear and elastic behavior for an embedded bar to concrete, the second-order differential equation that governs the bond behavior along the bond length can be stated as follow (Russo et al., 1990): 


$$
\frac{d^{2} \delta(x)}{d x^{2}}-J_{1} \tau(\delta(x))=0
$$

where $J_{1}$ is the ratio between the perimeter $\left(\pi d_{b}\right)$ and axial stiffness $\left(E_{l b} A_{b}\right)$ of the bar, being $d_{b}, E_{l b}$ and $A_{b}$ the diameter, the longitudinal modulus of elasticity and the cross-sectional area of the bar, respectively. In Eq. (1), $\delta(x)$ represents the slip between GFRP and surrounding concrete at a section $x$ from the free end. Based on the equilibrium condition along the bar, the following equations can also be deduced:

$$
\begin{gathered}
\sigma_{b}(x)=E_{l b} \frac{d \delta(x)}{d x} \\
\tau(x)=\frac{1}{J_{1}} \frac{d^{2} \delta(x)}{d x^{2}}
\end{gathered}
$$

where $\sigma_{b}$ and $\tau$ are the axial tensile stress of the bar and the bond shear stress of GFRP-SFRSCC interface respectively.

\section{Local Bond Stress-Slip Relationship}

A multi-linear diagram presented in Fig. 1, is proposed as local bond shear stress-slip $(\tau-\delta)$ relationship for embedded GFRP bar to SFRSCC in this study. This $\tau-\delta$ relationship is stated by the following equation:

$$
\tau(\delta)=\left\{\begin{array}{lll}
\tau_{0}+\frac{\tau_{m}-\tau_{0}}{\delta_{1}} \cdot \delta & 0 \leq \delta \leq \delta_{1} & \text { (elastic phase) } \\
\tau_{m} & \delta_{1}<\delta \leq \delta_{2} & \text { (plastic phase) } \\
\tau_{m}-\frac{\tau_{m}-\tau_{R}}{\delta_{3}-\delta_{2}} \cdot\left(\delta-\delta_{2}\right) & \delta_{2}<\delta \leq \delta_{3} & \text { (softening phase) } \\
\tau_{R} & \delta>\delta_{3} & \text { (frictional phase) }
\end{array}\right.
$$

The rigid branch $\left(0-\tau_{0}\right)$ represents the overall initial shear strength and it is attributable to the micro-mechanical and chemical properties of the involved materials and interfaces. The ascending branch represents the bond behavior between the initial bond shear stress $\left(\tau_{0}\right)$ and the bond strength $\left(\tau_{m}\right)$ ends at a slip $\delta_{1}$. Between $\delta_{1}$ and $\delta_{2}$, constant bond strength, $\tau_{m}$, simulates the initiation of the damage in the bar-concrete interface. With the advance of this damage, the bond stress starts decreasing with the increase of slip, and this slip-softening phase, which is governed by friction and micromechanical interlocking along the bond length, is simulated by the third branch that ends at a slip $\delta_{3}$, when a residual bond shear stress, $\tau_{R}$, is attained. For $\delta>\delta_{3}$, due to friction mechanism between bar and surrounding concrete, this residual bond stress is assumed constant, in agreement with previous research (Hao et al., 2008; Baena et al., 2009) and results obtained in the experimental tests.

\section{Theoretical Pullout Force in case of Infinite Bond Length}

Debonding process for infinite bond length of GFRP bar is described hereafter by introducing the proposed $\tau-\delta$ relationship in Eq. (4) into Eq. (1). For each phase, slip distribution along the bar, $\delta(x)$, required bond transfer length, 
$L_{t r}\left(\delta_{L}\right)$, and corresponding pullout force at each section of the bar, $F(x)$, are determined for whatever value of loaded end slip (imposed slip, $\left.\delta_{L}\right)$. These concepts, as well as the definition of the local reference systems in elastic $\left(x^{e}\right)$, plastic $\left(x^{p}\right)$, softening $\left(x^{s}\right)$ and frictional $\left(x^{f}\right)$ bond phases, are illustrated in Fig. 2. The study is based on the works carried out by Bianco et al. (2009) and Sena-Cruz and Barros (2004) in the case of NSM-CFRP laminate.

\section{Elastic phase}

When the imposed slip is $\delta_{L} \leq \delta_{1}$, Eq. (1) is solved in the local reference system of $x^{e}$, and the solution becomes (Bianco et al., 2009):

$$
\delta^{e}\left(x^{e}\right)=C_{1}^{e} e^{\lambda x^{e}}+C_{2}^{e} e^{-\lambda x^{e}}-C_{3}^{e}
$$

with

$$
\frac{1}{\lambda^{2}}=\frac{\delta_{1}}{\left(\tau_{m}-\tau_{0}\right) \cdot J_{1}}
$$

and the particular solution is

$$
C_{3}^{e}=\frac{\tau_{0} J_{1}}{\lambda^{2}}
$$

By imposing the following boundary conditions into Eq. (5)

$$
\left\{\begin{array}{l}
\delta^{e}=0 \text { at } x^{e}=0 \\
\delta^{e}=\delta_{L} \text { at } x^{e}=L_{t r}^{e}\left(\delta_{L}\right)
\end{array}\right.
$$

where $L_{t r}^{e}\left(\delta_{L}\right)$ is the bond transfer length corresponding to the first phase $\left(\delta_{L} \leq \delta_{1}\right)$, the integration constants are obtained as follows:

$$
\begin{gathered}
C_{1}^{e}=\left[\delta_{L}+C_{3}^{e} \cdot\left(1-e^{-\lambda \cdot L_{t r}^{e}\left(\delta_{L}\right)}\right)\right] \cdot \frac{1}{e^{\lambda \cdot L_{t r}^{e}\left(\delta_{L}\right)}-e^{-\lambda \cdot L_{t r}^{e}\left(\delta_{L}\right)}} \\
C_{2}^{e}=C_{3}^{e}-C_{1}^{e}
\end{gathered}
$$

By imposing the equilibrium equation along the bond length (i.e. $\left.F\left(x=L_{t r}\left(\delta_{L}\right)\right)=\pi d_{b} \cdot \int_{0}^{L_{t r}\left(\delta_{L}\right)} \tau\left(x^{e}\right) d x^{e}\right), L_{t r}^{e}\left(\delta_{L}\right)$ becomes:

$$
L_{t r}^{e}\left(\delta_{L}\right)=\frac{1}{\lambda} \cdot \operatorname{arcosh}\left(\frac{\delta_{L}+C_{3}^{e}}{C_{3}^{e}}\right)
$$

The pullout force at the value of imposed slip can be determined by using Eq. (2) 


$$
F\left(x=L_{t r}\left(\delta_{L}\right)\right)=F^{e}\left(x=L_{t r}^{e}\left(\delta_{L}\right)\right)=\pi d_{b} \int_{0}^{L_{t r}^{e}\left(\delta_{L}\right)} \tau\left(x^{e}\right) d x^{e}=\left.E_{l b} A_{b}\left(\frac{d \delta^{e}}{d x}\right)\right|_{0} ^{L_{t r}^{e}\left(\delta_{L}\right)}
$$

and the maximum pullout force and maximum bond transfer length undergoing the elastic phase $\left(F_{1}^{e}\right.$ and $L_{t r 1}$ respectively) are obtained by imposing a loaded end slip equals $\delta_{1}$ :

$$
\begin{gathered}
L_{t r 1}=L_{t r}^{e}\left(\delta_{L}=\delta_{1}\right) \\
F_{1}^{e}=F^{e}\left(x^{e}=L_{t r 1}\right)
\end{gathered}
$$

\section{Plastic Phase}

The plastic phase corresponds to the loaded end slip in the interval of $\delta_{1}<\delta_{L} \leq \delta_{2}$ and the corresponding bond shear stress remains constant $\left(\tau(\delta)=\tau_{m}\right)$. The solution for Eq. (1) is a polynomial function in the local reference system of $x^{p}$ as follow

$$
\delta^{p}\left(x^{p}\right)=C_{1}^{p}\left(x^{p}\right)^{2}+C_{2}^{p} x^{p}+C_{3}^{p}
$$

with

$$
C_{1}^{p}=\frac{\tau_{m} J_{1}}{2}
$$

The boundary conditions are

$$
\left\{\begin{array}{l}
\delta^{p}=\delta_{1} \text { at } x^{p}=0 \\
\delta^{p}=\delta_{L} \text { at } x^{p}=L_{t r}^{p}\left(\delta_{L}\right)
\end{array}\right.
$$

where $L_{t r}^{p}\left(\delta_{L}\right)$ is the bond transfer length in the plastic phase $\left(\delta_{1}<\delta_{L} \leq \delta_{2}\right)$ and the integration constants become

$$
\begin{gathered}
C_{2}^{p}=\frac{\left(\delta_{L}-\delta_{1}\right)-C_{1}^{p}\left(L_{t r}^{p}\left(\delta_{L}\right)\right)^{2}}{L_{t r}^{p}\left(\delta_{L}\right)} \\
C_{3}^{p}=\delta_{1}
\end{gathered}
$$

By imposing the equilibrium equation along the bond length (i.e. $\left.F\left(x=L_{t r}\left(\delta_{L}\right)\right)=\pi d_{b} \cdot \int_{0}^{L_{t r}^{p}\left(\delta_{L}\right)} \tau\left(x^{p}\right) d x^{p}+F_{1}^{e}\right)$, $L_{t r}^{p}\left(\delta_{L}\right)$ is obtained as the following closed-form equation:

$$
L_{t r}^{p}\left(\delta_{L}\right)=\frac{-F_{1}^{e}+\left[F_{1}^{e}+4 C_{1}^{p}\left(\delta_{L}-\delta_{1}\right)\right]^{0.5}}{2 C_{1}^{p}}
$$

and the overall bond transfer length is

$$
L_{t r}\left(\delta_{L}\right)=L_{t r 1}+L_{t r}^{p}\left(\delta_{L}\right)
$$


The pullout force for whatever value of the imposed slip in this phase is

$$
F^{p}\left(x^{p}=L_{t r}^{p}\left(\delta_{L}\right)\right)=\pi d_{b} \cdot \int_{0}^{L_{t r}^{p}\left(\delta_{L}\right)} \tau_{m} d x^{p}=\pi d_{b} \cdot L_{t r}^{p}\left(\delta_{L}\right) \cdot \tau_{m}
$$

and the total pullout force becomes

$$
F\left(x=L_{t r}\left(\delta_{L}\right)\right)=F_{1}^{e}+F^{p}\left(x^{p}=L_{t r}^{p}\left(\delta_{L}\right)\right)
$$

The maximum bond transfer length and maximum pullout force undergoing this phase can be also calculated by substituting $\delta_{L}$ by $\delta_{2}$ in Eqs. (20) and (22) respectively:

$$
\begin{gathered}
L_{t r 2}=L_{t r}^{p}\left(\delta_{L}=\delta_{2}\right) \\
F_{2}^{p}=F^{p}\left(x^{p}=L_{t r 2}\right)
\end{gathered}
$$

The total force at the end of this phase becomes

$$
F_{2}=F\left(x=L_{t r}\left(\delta_{L}=\delta_{2}\right)\right)=F_{1}^{e}+F_{2}^{p}
$$

\section{Softening Phase}

For $\delta_{2}<\delta_{L} \leq \delta_{3}$, the corresponding bond shear stress, $\tau\left(\delta_{L}\right)$, decreases up to attain the residual bond shear stress, $\tau_{R}$, at $\delta_{L}=\delta_{3}$ (Fig. 1). Introducing into Eq. (1) the corresponding function of Eq. (4) yields a function in the local coordinate system of $x^{s}$ as follow (Bianco et al., 2009):

$$
\delta^{s}\left(x^{s}\right)=C_{1}^{s} \cdot \sin \left(\beta \cdot x^{s}\right)+C_{2}^{s} \cdot \cos \left(\beta \cdot x^{s}\right)+C_{3}^{s}
$$

with

$$
\frac{1}{\beta^{2}}=\frac{\left(\delta_{3}-\delta_{2}\right)}{\left(\tau_{m}-\tau_{R}\right) J_{1}}
$$

and particular solution becomes

$$
C_{3}^{s}=\frac{\tau_{m} J_{1}}{\beta^{2}}+\delta_{2}
$$

By considering the relevant boundary conditions of the softening phase

$$
\left\{\begin{array}{l}
\delta^{s}=\delta_{2} \text { at } x^{s}=0 \\
\delta^{s}=\delta_{L} \text { at } x^{s}=L_{t r}^{s}\left(\delta_{L}\right)
\end{array}\right.
$$

where $L_{t r}^{s}\left(\delta_{L}\right)$ is the bond transfer length in the softening phase $\left(\delta_{2}<\delta_{L} \leq \delta_{3}\right)$, the integration constants are obtained from 


$$
\begin{gathered}
C_{1}^{s}=\frac{1}{\sin \left(\beta \cdot L_{t r}^{s}\left(\delta_{L}\right)\right)} \cdot\left\{\delta_{L}-\delta_{2}+\frac{\tau_{m} \cdot J_{1}}{\beta^{2}} \cdot\left[\cos \left(\beta \cdot L_{t r}^{s}\left(\delta_{L}\right)\right)-1\right]\right\} \\
C_{2}^{s}=\delta_{2}-C_{3}^{s}
\end{gathered}
$$

The equilibrium condition along the bond length (i.e. $F\left(x=L_{t r}\left(\delta_{L}\right)\right)=\pi d_{b} \cdot \int_{0}^{L_{t r}^{s}\left(\delta_{L}\right)} \tau\left(x^{s}\right) d x^{s}+F_{2}^{p}+F_{1}^{e}$ ) is used to derive the bond transfer length as function of $\delta_{L}$. So, $L_{t r}^{S}\left(\delta_{L}\right)$ can be expressed by (Bianco et al., 2009)

$$
L_{t r}^{s}\left(\delta_{L}\right)=\frac{1}{\beta} \cdot\left[\phi+\arcsin \frac{C_{s}}{\sqrt{\left(A_{s}\right)^{2}+\left(B_{s}\right)^{2}}}\right]
$$

with

$$
\begin{gathered}
A_{s}=F_{1}^{e}+F_{2}^{p}=F_{2} \\
B_{s}=\pi d_{b} \cdot \frac{\tau_{m}}{\beta} \\
C_{s}=\frac{\pi d_{b} \cdot \beta}{J_{1}} \cdot\left(\delta_{L}-C_{3}^{s}\right)
\end{gathered}
$$

and

$$
\phi=\operatorname{asin}\left(\frac{B_{s}}{\sqrt{A_{s}^{2}+B_{s}^{2}}}\right)
$$

and the overall bond transfer length at the end of the softening phase is

$$
L_{t r}\left(\delta_{L}\right)=L_{t r 1}+L_{t r 2}+L_{t r}^{s}\left(\delta_{L}\right)
$$

The pullout force for whatever value of imposed slip in this phase is calculated by means of Eq. (39)

$$
F^{s}\left(x^{s}=L_{t r}^{s}\left(\delta_{L}\right)\right)=\pi d_{b} \int_{0}^{L_{t r}^{s}\left(\delta_{L}\right)} \tau\left(x^{s}\right) d x^{s}=\left.E_{l b} A_{b}\left(\frac{d \delta^{s}}{d x^{s}}\right)\right|_{0} ^{L_{t r}^{s}\left(\delta_{L}\right)}
$$

and the total pullout force becomes

$$
F\left(x=L_{t r}\left(\delta_{L}\right)\right)=F_{1}^{e}+F_{2}^{p}+F^{s}\left(x^{s}=L_{t r}^{s}\left(\delta_{L}\right)\right)
$$

The maximum bond transfer length and the corresponding pullout force in this phase are calculated for a value of imposed slip equals to $\delta_{3}$ :

$$
L_{t r 3}=L_{t r}^{s}\left(\delta_{L}=\delta_{3}\right)
$$




$$
F_{3}^{s}=F\left(x^{s}=L_{t r 3}\right)
$$

The total force at the end of the softening phase becomes

$$
F_{3}=F\left(x=L_{t r}\left(\delta_{L}=\delta_{3}\right)\right)=F_{1}^{e}+F_{2}^{p}+F_{3}^{s}
$$

\section{Frictional Phase}

When $\delta_{L}>\delta_{3}, \tau(\delta)$ equals to a constant value of bond shear stress (i.e. $\tau_{R}$ ) due to a stable amount of interfacial friction is established between GFRP and surrounding SFRSCC. Therefore, the solution for Eq. (1) is a polynomial function similar to the plastic phase:

$$
\delta^{f}\left(x^{f}\right)=C_{1}^{f}\left(x^{f}\right)^{2}+C_{2}^{f} x^{f}+C_{3}^{f}
$$

with

$$
C_{1}^{f}=\frac{\tau_{R} J_{1}}{2}
$$

and relevant boundary conditions are

$$
\left\{\begin{array}{l}
\delta^{f}=\delta_{3} \text { at } x^{f}=0 \\
\delta^{f}=\delta_{L} \text { at } x^{f}=L_{t r}^{f}\left(\delta_{L}\right)
\end{array}\right.
$$

where $L_{t r}^{f}\left(\delta_{L}\right)$ is the bond transfer length for $\delta_{L}>\delta_{3}$. By imposing these boundary conditions into Eq. (44), the integration constants become

$$
\begin{gathered}
C_{2}^{f}=\frac{\left(\delta_{L}-\delta_{3}\right)-C_{1}^{f}\left(L_{t r}^{f}\left(\delta_{L}\right)\right)^{2}}{L_{t r}^{f}\left(\delta_{L}\right)} \\
C_{3}^{f}=\delta_{3}
\end{gathered}
$$

and using equilibrium equation (i.e. $\left.F\left(x=L_{t r}\left(\delta_{L}\right)\right)=\pi d_{b} \cdot \int_{0}^{L_{t r}^{f}\left(\delta_{L}\right)} \tau\left(x^{f}\right) d x^{f}+F_{3}^{s}+F_{2}^{p}+F_{1}^{e}\right), L_{t r}^{f}\left(\delta_{L}\right)$ is calculated by:

$$
L_{t r}^{f}\left(\delta_{L}\right)=\frac{F_{3}-\left[F_{3}+4 C_{1}^{f}\left(\delta_{L}-\delta_{3}\right)\right]^{0.5}}{2 C_{1}^{f}}
$$

The pullout force for whatever value of $\delta_{L}>\delta_{3}$ is obtained by using

$$
F^{f}\left(x^{f}=L_{t r}^{f}\left(\delta_{L}\right)\right)=\pi d_{b} \int_{0}^{L_{t r}^{f}\left(\delta_{L}\right)} \tau_{R} d x^{f}=\pi d_{b} \cdot L_{t r}^{f}\left(\delta_{L}\right) \cdot \tau_{R}
$$

and the total pullout force is calculated by

$$
F\left(x=L_{t r}\left(\delta_{L}\right)\right)=F_{1}^{e}+F_{2}^{p}+F_{3}^{s}+F^{f}\left(x^{f}=L_{t r}^{f}\left(\delta_{L}\right)\right)
$$




\section{Theoretical Pullout Force for Finite Bond Length}

In case of finite bond length, the debonding process for embedded GFRP bars (or other types of bars) into concrete can also be analyzed by solving Eq. (1) imposing appropriate boundary conditions for slip at the extremity of the bond transfer length $\left(L_{t r}\right)$, which cannot be exceed of an available finite bond length $\left(L_{f}\right)$. While slip at free end $\left(\delta_{F}\right)$ is null, i.e. $L_{f}>L_{t r}$, the pullout force for whatever value of $\delta_{L}$ is directly obtained by using Eqs. (12), (23), (40) and (51). However, when $\delta_{F}>0$, i.e. $L_{f} \leq L_{t r}$, and two or more bond-slip phases are acting over $L_{f}$, deriving closed-form equations for pullout force $\left(F\left(\delta_{L}\right)\right)$ is not straightforward due to the complexity of the equations. To overcome this complexity, Bianco et al. (2009) presented a bond model for NSM-CFRP strips taking a three-linear bond-slip relationship (one ascending and two descending branches) by assuming that the slip distribution $(\delta(x))$ for infinite bond length condition could also be applied to finite bond length condition. That is, the closed-form equations developed for case of infinite bond length were directly used for finite length by considering the possible configurations between $L_{f}$ and $L_{t r}$ (Bianco et al., 2009). Mazaheripour et al. (2012b) used this bond model by taking a four-linear bond-slip relationship for GFRP bars similar to that which is shown in Fig. 1. Although this model was capable of predicting with good accuracy the pullout force versus loaded end slip curves recorded in the experimental tests, the model was not capable to estimate slip at free loaded end, specifically for $L_{f}>10 d_{b}$.

In the present study, an analytical-numerical method is presented to determine the pullout force $(F)$ as well as $\delta_{F}$ for whatever value of $\delta_{L}$ in case of a finite bond length $\left(L_{f}\right)$ by taking the relevant boundary conditions at free and loaded ends (i.e. $\delta=\delta_{L}$ at $x=L_{f}$ and $\delta=\delta_{F}$ at $x=0$ ) and not assuming the same $\delta(x)$ of infinite bond length condition. Therefore, for each bond phases, new values are derived for those integration constants in Eq. (5), (15), (27) and (44) and, consequently, new $\delta(x)$ is determined over the $L_{f}$. The calculation of pullout force, as well as slip at free end for whatever value of imposed slip in case of finite bond length condition is described hereafter by considering different configurations of the proposed bond phases over the $L_{f}$.

\section{When One Bond Phase is Acting Over $L_{f}$}

\section{Fully Elastic}

When $\delta_{L} \leq \delta_{1}$ and $\delta_{1}>\delta_{F}>0$, that is, $L_{f}$ is thoroughly covered by the linear elastic phase (see Fig. 3a); Eqs. (9) and (10) become

$$
\begin{gathered}
C_{1}^{e}=\left[\left(\delta_{L}-\delta_{F}\right)+C_{3}^{e} \cdot\left(1-e^{-\lambda \cdot L_{f}}\right)\right] \cdot \frac{1}{e^{\lambda \cdot L_{f}}-e^{-\lambda \cdot L_{f}}} \\
C_{2}^{e}=\left(\delta_{F}+C_{3}^{e}\right)-C_{1}^{e}
\end{gathered}
$$

and using equilibrium condition, leads to express $\delta_{F}$ as function of $\delta_{L}$ : 


$$
\delta_{F}=\frac{\left(\delta_{L}+C_{3}^{e}\right)}{\cosh \left(\lambda L_{f}\right)}-C_{3}^{e}
$$

The pullout force is calculated by adopting Eqs. (52) and (53)

$$
F^{e}\left(x^{e}=L_{f}\right)=A_{b} \sigma_{b}\left(x^{e}=L_{f}\right)=E_{l b} A_{b} \cdot\left(C_{1}^{e}\left(\delta_{L}\right) \cdot \lambda e^{\lambda L_{f}}-C_{2}^{e}\left(\delta_{L}\right) \cdot \lambda e^{\lambda L_{f}}\right)
$$

\section{Fully Plastic}

If $\delta_{F}>\delta_{1}$ and $\delta_{L} \leq \delta_{2}, L_{f}$ undergoes only the plastic phase (see Fig. 3b). The integration of constants in Eqs. (18) and (19) become

$$
\begin{gathered}
C_{2}^{p}=\frac{\left(\delta_{L}-\delta_{F}\right)-C_{1}^{p}\left(L_{f}\right)^{2}}{L_{f}} \\
C_{3}^{p}=\delta_{F}
\end{gathered}
$$

$\delta_{F}$ is also determined by considering equilibrium condition

$$
\delta_{F}=\delta_{L}-C_{1}^{p}\left(L_{f}\right)^{2}
$$

and $F$ is simply obtained by using

$$
F^{p}\left(x^{p}=L_{f}\right)=L_{f} \pi d_{b} \tau_{m}
$$

\section{Fully Softening}

For the case shown in Fig. 3c, $L_{f}$ fully undergoes softening. Thus, the integration of constants in Eqs. (31) and (32) become

$$
\begin{gathered}
C_{1}^{s}=\frac{1}{\sin \left(\beta \cdot L_{f}\right)} \cdot\left\{\delta_{L}-\delta_{F}+\frac{\tau_{m} \cdot J_{1}}{\beta^{2}} \cdot\left[\cos \left(\beta \cdot L_{f}\right)-1\right]\right\} \\
C_{2}^{s}=\delta_{F}-C_{3}^{s}
\end{gathered}
$$

and $\delta_{F}$ can be expressed as function of $\delta_{L}$ by using the equilibrium condition

$$
\delta_{F}=\delta_{L}-\frac{\tau_{m} J_{1}}{\beta^{2}} \cos \left(\beta \cdot L_{f}\right)+\left(C_{3}^{s}-\delta_{2}\right)
$$

Therefore, $F$ is obtained by Eq. (62) adopting Eqs. (60) and (61)

$$
F^{s}\left(x^{s}=L_{f}\right)=\pi d_{b} \int_{0}^{L_{f}} \tau\left(x^{s}\right) d x^{s}=\left.E_{l b} A_{b}\left(\frac{d \delta^{s}}{d x^{s}}\right)\right|_{0} ^{L_{f}}
$$

\section{Fully Frictional}

If $\delta_{F}>\delta_{3}$ and $\delta_{L}>\delta_{3}$, the frictional bond phase is acting over $L_{f}$ (see Fig. $3 \mathrm{~d}$ ). Similar to the fully plastic condition, the integration of the constants in Eqs. (47) and (48) become 


$$
\begin{gathered}
C_{2}^{f}=\frac{\left(\delta_{L}-\delta_{F}\right)-C_{1}^{f}\left(L_{f}\right)^{2}}{L_{f}} \\
C_{3}^{f}=\delta_{F}
\end{gathered}
$$

and $\delta_{F}$ is derived as follow

$$
\delta_{F}=\delta_{L}-C_{1}^{f}\left(L_{f}\right)^{2}
$$

$F$ is simply obtained by using

$$
F^{f}\left(x^{f}=L_{f}\right)=L_{f} \pi d_{b} \tau_{R}
$$

\section{When Two or More Bond Phases are Acting Over $L_{f}$}

When two or more bond phases are acting over the $L_{f}$, a numerical strategy was adopted in the present study to obtain the slip and force (or bond stress) distributions. That is, by taking a small increment for the imposed slip at $i^{\text {th }}$ step of the calculations (i.e. $\delta_{L}^{i}=\delta_{L}^{i-1}+\Delta \delta_{L}$ ) and initially using the value of the pullout force at the last converged step of the calculation, $(i-1)^{\mathrm{th}}$, for each bond phase (i.e. $\left(F^{e}\right)^{i-1},\left(F^{p}\right)^{i-1},\left(F^{s}\right)^{i-1}$ and $\left.\left(F^{f}\right)^{i-1}\right)$, a new value of the pullout force $\left(F^{i}=F^{i-1}+\Delta F\right)$ is calculated.

\section{Elastic-Plastic (Fig. 4a)}

By imposing $\delta_{L}^{i},\left(L_{t r}^{p}\right)^{i}$ is calculated by Eq. (20) where $F_{1}^{e}$ is replaced by $\left(F^{e}\right)^{i-1}$. Being obtained $\left(L_{t r}^{p}\right)^{i},\left(L_{t r}^{e}\right)^{i}$ is simply derived by $L_{f}-\left(L_{t r}^{p}\right)^{i}$. Therefore, $\left(\delta_{F}\right)^{i}$ and $\left(F^{e}\right)^{i}$ are calculated by Eqs. (54) and (55) respectively at $x^{e}=\left(L_{t r}^{e}\right)^{i} .\left(F^{p}\right)^{i}$ is also calculated from Eq. (59) at $x^{p}=\left(L_{t r}^{p}\right)^{i}$. The total force becomes

$$
F^{i}=\left(F^{e}\right)^{i}+\left(F^{p}\right)^{i}
$$

\section{Plastic-Softening (Fig. 4b)}

For $\delta_{L}^{i},\left(L_{t r}^{s}\right)^{i}$ is calculated by means of Eq. (33) where $F_{1}^{e}$ is null and $F_{2}^{p}$ is substituted by $\left(F^{p}\right)^{i-1}$. Being obtained $\left(L_{t r}^{s}\right)^{i},\left(L_{t r}^{p}\right)^{i}$ is simply obtained by $L_{f}-\left(L_{t r}^{s}\right)^{i}$. Therefore, $\left(F^{p}\right)^{i}$ and $\left(\delta_{F}\right)^{i}$ are calculated by Eqs. (58) and (59) respectively at $x^{p}=\left(L_{t r}^{p}\right)^{i} \cdot\left(F^{s}\right)^{i}$ is also calculated from Eq. (63) at $x^{s}=\left(L_{t r}^{s}\right)^{i}$. The total force becomes

$$
F^{i}=\left(F^{p}\right)^{i}+\left(F^{s}\right)^{i}
$$

\section{Softening-Frictional (Fig. 4c)}

Here by imposing an increment for the imposed slip, $\left(L_{t r}^{f}\right)^{i}$ is calculated by Eq. (49) where $F_{1}^{e}$ and $F_{1}^{p}$ are null and $F_{3}^{s}$ is substituted by $\left(F^{s}\right)^{i-1}$. Being obtained $\left(L_{t r}^{f}\right)^{i},\left(L_{t r}^{s}\right)^{i}$ is simply calculated by $L_{f}-\left(L_{t r}^{f}\right)^{i}$. Hence, $\left(F^{s}\right)^{i}$ and $\left(\delta_{F}\right)^{i}$ 
are determined by Eqs. (62) and (63) respectively at $x^{s}=\left(L_{t r}^{s}\right)^{i} \cdot\left(F^{f}\right)^{i}$ is also determined by Eq. (67) at $x^{f}=\left(L_{t r}^{f}\right)^{i}$. The total force becomes

$$
F^{i}=\left(F^{s}\right)^{i}+\left(F^{f}\right)^{i}
$$

\section{Elastic-Plastic-Softening (Fig. 5a)}

For small increment of imposed slip, $\left(L_{t r}^{s}\right)^{i}$ is calculated by Eq. (33) where $F_{1}^{e}$ and $F_{2}^{p}$ are substituted by $\left(F^{e}\right)^{i-1}$ and $\left(F^{p}\right)^{i-1}$ respectively. Additionally, $\left(L_{t r}^{p}\right)^{i}$ is determined by Eq. (20) where $F_{1}^{e}$ is also replaced by $\left(F^{e}\right)^{i-1}$.

Therefore, $\left(L_{t r}^{s}\right)^{i}$ is given by

$$
\left(L_{t r}^{e}\right)^{i}=L_{f}-\left(L_{t r}^{p}\right)^{i}-\left(L_{t r}^{s}\right)^{i}
$$

Since free loaded end undergoes elastic bond phase, $\left(\delta_{F}\right)^{i}$ is calculated by Eq. (54) at $x^{e}=\left(L_{t r}^{e}\right)^{i}$. Then, $\left(F^{e}\right)^{i}$ is calculated by Eq. (55) at $x^{e}=\left(L_{t r}^{e}\right)^{i},\left(F^{p}\right)^{i}$ by Eq. (59) at $x^{p}=\left(L_{t r}^{p}\right)^{i}$, and $\left(F^{s}\right)^{i}$ by Eq. (63) at $x^{s}=\left(L_{t r}^{s}\right)^{i}$. The total pullout force becomes

$$
F^{i}=\left(F^{e}\right)^{i}+\left(F^{p}\right)^{i}+\left(F^{s}\right)^{i}
$$

\section{Plastic-Softening-Frictional (Fig. 5b)}

Similar to the previous configuration, $\left(L_{t r}^{f}\right)^{i}$ is calculated by Eq. (49) where $F_{1}^{e}$ is null and $F_{2}^{p}$ and $F_{3}^{s}$ are substituted by $\left(F^{p}\right)^{i-1}$ and $\left(F^{s}\right)^{i-1}$ respectively. Besides, $\left(L_{t r}^{s}\right)^{i}$ is determined by Eq. (33) where $F_{1}^{e}$ is null and $F_{2}^{p}$ is also replaced by $\left(F^{p}\right)^{i-1}$. Finally, $\left(L_{t r}^{p}\right)^{i}$ is given by

$$
\left(L_{t r}^{p}\right)^{i}=L_{f}-\left(L_{t r}^{s}\right)^{i}-\left(L_{t r}^{f}\right)^{i}
$$

Since free end undergoes plastic phase, $\left(\delta_{F}\right)^{i}$ is derived by Eq. (58) at $x^{p}=\left(L_{t r}^{p}\right)^{i}$. Then, $\left(F^{p}\right)^{i},\left(F^{s}\right)^{i}$ and $\left(F^{f}\right)^{i}$ are obtained by Eqs. (59) at $x^{p}=\left(L_{t r}^{p}\right)^{i},(63)$ at $x^{s}=\left(L_{t r}^{s}\right)^{i}$ and (67) at $x^{f}=\left(L_{t r}^{f}\right)^{i}$ respectively. The total pullout force becomes

$$
F^{i}=\left(F^{p}\right)^{i}+\left(F^{s}\right)^{i}+\left(F^{f}\right)^{i}
$$

\section{Elastic-Plastic-Softening-Frictional (Fig. 6)}

When $\delta_{L}>\delta_{3}$ and $L_{t r}\left(\delta_{L}\right)<L_{f}, L_{f}$ undergoes simultaneously the four proposed bond phases. By imposing a small increment for $\delta_{L}$, the same strategy can be also applied in this case to determine $\left(L_{t r}^{p}\right)^{i},\left(L_{t r}^{s}\right)^{i}$ and $\left(L_{t r}^{f}\right)^{i}$ by initially taking $F_{1}^{e}, F_{2}^{p}$ and $F_{3}^{s}$ equal to $\left(F^{e}\right)^{i-1},\left(F^{p}\right)^{i-1}$ and $\left(F^{s}\right)^{i-1}$ respectively. Then, $\left(L_{t r}^{e}\right)^{i}$ is given by

$$
\left(L_{t r}^{e}\right)^{i}=L_{f}-\left(L_{t r}^{p}\right)^{i}-\left(L_{t r}^{s}\right)^{i}-\left(L_{t r}^{f}\right)^{i}
$$

and the following equation gives the total pullout force: 


$$
F^{i}=\left(F^{e}\right)^{i}+\left(F^{p}\right)^{i}+\left(F^{s}\right)^{i}+\left(F^{f}\right)^{i}
$$

The flowchart of the proposed analytical-numerical algorithm is presented in Fig. 7. In all above cases, once $\left(L_{t r}\right)^{i}$ is obtained for the all active bond phase (e.g. Elastic, Plastic and Softening are the active bond phase in case of Fig. 5a), the values of $\left(F^{e}\right)^{i-1},\left(F^{p}\right)^{i-1},\left(F^{s}\right)^{i-1}$ and $\left(F^{f}\right)^{i-1}$ are substituted respectively by the new calculated values of $\left(F^{e}\right)^{i}$, $\left(F^{p}\right)^{i},\left(F^{s}\right)^{i}$ and $\left(F^{f}\right)^{i}$. Then, $\left(L_{t r}\right)^{i}$ is recalculated until achieving a value of error less than a tolerance adopted for $\Delta L_{t r}$. This calculation loop is also illustrated in the flowchart.

\section{Outline of the experimental work}

An experimental program comprising 36 pullout bending specimens was carried out by Mazaheripour et al. (2012a) in order to assess the bond behavior of GFRP bars embedded into SFRSCC. A test setup similar to that recommended by RILEM for case of steel bars was adopted. The test setup and the measuring devices are schematically shown in Figure 8. Two types of GFRP bars of ribbed ( 8 and $12 \mathrm{~mm}$ diameter) and smooth surface (only $12 \mathrm{~mm}$ diameter) that are commercially produced by European companies were utilized in the experimental tests. According to the data sheet provided by the suppliers, Young's modulus of the ribbed and smooth GFRP bars are, respectively, 56 and 49 GPa, while the ultimate tensile strengths are $1350 \mathrm{MPa}$ and $1000 \mathrm{MPa}$. Additionally, a series of five notched beam bending tests (named as NB1 to 5) was carried out according to recommendations by CEB-FIP MC2010 in order to characterize the post-cracking behavior of the developed SFRSCC with $60 \mathrm{~kg} / \mathrm{m}^{3}$ of hooked ends steel fibers (length and diameter of 33 $\mathrm{mm}$ and $0.55 \mathrm{~mm}$, respectively, and ultimate tensile strength of $1100 \mathrm{MPa}$ ). Figure 9 shows the configuration of notched beam bending test and the results in terms of Force-CMOD (crack mouth opening displacement) at notched cross section. Based on the force values, the derived residual flexural tensile stress parameters, $f_{\mathrm{R}}$, were determined by

$$
f_{R}=\frac{3 P L}{2 b h_{s p}{ }^{2}}
$$

where $P$ is the applied load; $b$ and $h_{s p}$ are the width and the height of the notched section, respectively. The values of $f_{R}$ are also shown in the secondary vertical axis in Fig. 9. Moreover, the main mechanical properties of SFRSCC are included in Table 1.

In the bond tests, three bond lengths $\left(L_{f}\right)$ of 5, 10 and 20 times of bar diameter $\left(d_{b}\right)$ and two concrete cover thicknesses ( $C=15$ and $30 \mathrm{~mm}$ ) were the parameters whose influence on the bond behavior of GFRP/SFRSCC was investigated. With an exception of one pullout bending specimen regarding to GFRP bar of $8 \mathrm{~mm}$ diameter and $20 d_{b}$ bond length, the remaining ones failed by debonding in which a residual pullout force was recorded for all of them. In case of ribbed GFRP 
bars with concrete cover of $15 \mathrm{~mm}$, a single crack appeared along the embedment length. However, splitting failure mode never occurred due to the contribution of fibers bridging this crack that had maintained the crack width at very small value. The reader is directed to the paper by Mazaheripour et al. (2012a) for more details about the experimental results.

\section{Predictive Performance of the Bond Model}

To assess the predictive performance of the proposed bond model, the obtained $F-\delta$ from the model is compared with the results registered in the previously described bond tests. The values of the parameters to define the $\tau-\delta$ relationship in the model were calibrated using inverse analysis by minimizing the absolute value of error $(e)$ which is defined as $\left|A_{F-\delta}^{\text {the }}-A_{F-\delta}^{\exp }\right| / A_{F-\delta}^{\exp } \times 100$, where $A_{F-\delta}^{\exp }$ is the area under the average $F-\delta$ of the experimental curves, and $A_{F-\delta}^{\text {the }}$ is the area of the F- $\delta$ obtained theoretically. Table 1 presents the results of the inverse analysis as well as the error $(e)$, in percentage. In this table, the following experimental results are also reported: the maximum pullout force $\left(F_{\text {max }}\right)$; its corresponding loaded end slip $\left(\delta_{m}\right)$ and the residual pullout force at the end of the tests $\left(F_{\text {res }}\right)$ which was calculated for a pullout force corresponding to the relatively high value of slip $(8 \mathrm{~mm})$, when for all the specimens the debonding process was in the post-peak pullout force.

\section{Loaded End Slip}

The $F-\delta_{L}$ relationship registered experimentally and determined by the proposed bond model are compared in Fig. 10 and 11 for deformed and smooth GFRP bars, respectively. The results for the $8 \mathrm{~mm}$ bar diameter were not considered in the present study. This comparison evidences that the proposed method is capable of simulating with good accuracy the pullout force versus loaded end slip for the two types of GFRP bars. Moreover, the abrupt decay registered in the specimens reinforced with smooth GFRP bar's surface and $20 d_{b}$ bond length (see Fig. 11) was properly captured by using the proposed bond model, whereas the previously developed model by Mazaheripour et. al. 2012b was practically unable to simulate this behavior.

\section{Free End Slip}

Figs. 12 and 13 compare the experimental and theoretical $F-\delta_{F}$ relationships. As shown, the proposed bond model also predicts with acceptable accuracy the slip at free loaded end. To understand better this accuracy, Fig. 14 represents the relationship between $\delta_{L}$ and $\delta_{F}$ obtained experimentally and theoretically for the specimens with $L_{f}=20 d_{b}$. As shown, the $\delta_{L}-\delta_{F}$ curve obtained by the proposed bond model is in agreement with the experimental $\delta_{L}-\delta_{F}$ curve for both GFRP bars. This confirms the accurate prediction of the obtained $\delta(x)$ by the proposed bond model. 


\section{Observations}

\section{“Material” versus "structural” bond-slip property}

Like in the present paper, the slip between bar and surrounding concrete is currently measured at the free and loaded ends by using displacement transducers. The slip is, therefore, the relative deformation between the concrete zones where the transducer is supported, and the section of the FRP bar where the other extremity of the sensor is connected. This means that the measure recorded by this sensor is always affected by the deformation of the concrete zone supporting the transducer, which is a quantity difficult to obtain with accuracy. By bonding strain gauges to the FRP bar along the embedment length is also another common alternative to measure indirectly the slip. Nevertheless, the slip variation along the embedment length can only be representative if a reasonable number of strain gauges are applied, which has, however, a detrimental effect on the bond conditions between the bar and the surrounding concrete. Furthermore, the strategy of converting strain values from these strain gauges into a slip concept between bar and surrounding materials is quite arguable, and only admissible if negligible deformation is assumed for the surrounding concrete. Considering all these aspects, a local bond-slip relationship only exists, and therefore considered as a material property, when the deformation and damage in the surrounding concrete is much smaller than the deformation in the FRP bar. This means that a local bond-slip relationship is a material property only if assessed from experimental data corresponding to FRP-concrete bond length short enough to avoid significant deformation and damage in the surrounding concrete. For the other cases the bond-slip relationship is a structural property, since the sensors are affected by the relevant deformation and damage formed in the surrounding concrete.

Due to these reasons, the bond length possibilities adopted in the present research are relatively small in order to maintain the deformability and the damages relatively small compared to the deformability of the FRP bars. Furthermore, due to the crack arrestment provided by the fibers bridging the micro-cracks, the damage due to crack formation in the surrounding concrete became limited. Therefore, for modeling the bond behavior between the GFRP bars and the SFRSCC considered in the present work, the bond-slip relationship derived from the tests with the lowest embedment length is recommended.

\section{Theoretical bond strength and its corresponding slip}

Taking the results from Table 2, which were obtained from inverse analysis, the influence of the bond length $\left(L_{f}\right)$ on the value of the bond strength $\left(\tau_{m}\right)$ is represented in Fig. 15a. The $\tau_{m}$ shows tendency to decrease with the increase of $L_{f}$ for a fixed concrete cover and type of GFRP bar. Additionally, the value of $\tau_{m}$ in case of $30 \mathrm{~mm}$ concrete cover was higher than that for $15 \mathrm{~mm}$. The $\tau_{m}$ was also higher in deformed bar than in smooth bar's surface. However, in case of $15 \mathrm{~mm}$ concrete cover thickness, $\tau_{m}$ was similar for both types of GFRP bars, because the relatively low confinement provided 
by this concrete cover thickness is not enough to mobilize the advantages of deformed bar surface characteristics. Hence, concrete cover higher than $15 \mathrm{~mm}(>1.25 \phi)$ is recommended for deformed GFRP bars in order to attain higher magnitude of bond strength $\left(\tau_{m}\right)$.

The influence of increasing $L_{f}$ on the slip at the end of the plastic phase, $\delta_{2}$, is also shown in Fig. $15 \mathrm{~b}$. By increasing $L_{f}$, $\delta_{2}$ increased for both types of GFRP bar. This means that $\delta_{2}$ is another parameter of the bond-slip constitutive law has increased with $L_{f}$ for the same type of bar, concrete and concrete cover thickness.

\section{Parametric study}

Hereafter, a parametric study was carried out to evaluate the influence of the involved parameters on the maximum pullout force $\left(F_{\max }\right)$, namely: the bond shear strength $\left(\tau_{m}\right)$ and its corresponding slips $\left(\delta_{1}\right.$ and $\left.\delta_{2}\right)$, bond length $\left(L_{f}\right)$, longitudinal Young's modulus of the bar $\left(E_{l b}\right)$, and the slip corresponds to the end of softening phase $\left(\delta_{3}\right)$ of bond-slip constitutive law. The study comprised six stages and for each stage, the influence of one parameter on $F_{\max }$ was appraised by considering three different values for $L_{f}\left(5,10\right.$ and $20 d_{b}$ bond length) while a constant value was given to the rest of the parameters. Table 2 presents the range of given values to the parameter at each stage. The initial bond stress $\left(\tau_{0}\right)$ and bar diameter $\left(d_{b}\right)$ considered as $1.0 \mathrm{MPa}$ and $12 \mathrm{~mm}$ in all cases, respectively. Fig. 16(a) to (f) show the results of this parametric study. As shown, $F_{\max }$ is significantly influenced by $L_{f}$ and $\tau_{m}$ (see Fig. 16a and b). The influence of $\delta_{1}$ and $\delta_{3}$ depends on the value given to $\delta_{2}$. When the values of $\delta_{2}$ and $\delta_{1}$ (or $\delta_{2}$ and $\delta_{3}$ ) are close to each others, their influence on $F_{\max }$ is more visible (see Fig. 16(c) and (e)). On the whole, the impact of all these slip values and also the magnitude of $E_{l b}$ on the $F_{\max }$ are not significant when the $L_{f}<20 d_{b}$.

\section{Theoretical Development Length}

The minimum transferred bond length required to reach the ultimate tensile stress $\left(\sigma_{b u}\right)$ in the bar can be predicted by means of the proposed bond model. Based on the results of the pullout tests carried out by Mazaheripour et al. (2012a), the minimum development length of the GFRP bars would be higher than $20 d_{b}$ since no tensile rupture reported for the GFRP bars in that study (with an exception of one specimen). On the other hand, according to the paramedic study presented in this paper, among the set of local bond-slip law's parameters, only $L_{f}$ and $\tau_{m}$ showed significant influence on the maximum pullout force. Therefore, $\tau_{m}$ was defined as function of the bond length $\left(L_{f}\right)$ in the proposed bond model. Accepting exponential fit for the $\tau_{m}-L_{f}, \tau_{m}$ can be estimated with the following expression:

$$
\tau_{m}\left(L_{f}\right)=b_{1}\left(L_{f}\right)^{b_{2}}
$$


where $b_{1}$ and $b_{2}$ are the constant values fit the equation with the test results of different bond length (see Fig. 15a). By imposing Eq. (78) into the model instead of $\tau_{m}$, the maximum pullout force is obtained for whatever value of $L_{f}$. The other parameters adopted in the bond model are summarized in Table 4.

Fig. 17 shows the achievable theoretical tensile stress $\left(\sigma_{b}\right)$ for whatever value of $\left(L_{f} / d_{b}\right)$ obtained from the bond model. These results were also compared with those values calculated from the formulation of several codes by means of the Eqs. (79), (80), (81) and (82) for given $L_{f} / d_{b}$ and $C / d_{b}$ :

$$
\begin{gathered}
\sigma_{b}=\frac{0.083 \sqrt{f_{c}^{\prime}}}{\alpha}\left(13.6 \frac{L_{f}}{d_{b}}+\frac{C}{d_{b}} \frac{L_{f}}{d_{b}}+340\right) \quad \text { (ACI 2006) } \\
\sigma_{b}=1.25 \sqrt{f_{c}^{\prime}}\left(0.318\left(\frac{L_{f}}{d_{b}}\right)+0.795\left(\frac{C}{d_{b}}\right)\left(\frac{L_{f}}{d_{b}}\right)+13.3\right) \quad \text { (JSCE 1997) } \\
\sigma_{b}=54\left(\frac{f_{c}^{\prime}}{25}\right)^{0.25}\left(\frac{25}{d_{b}}\right)^{0.20}\left(\frac{L_{f}}{d_{b}}\right)^{0.55}\left(\frac{C}{d_{b}}\right)^{0.33}\left(\frac{C_{\max }}{C}\right)^{0.1} \quad \text { (fib 2010) } \\
\sigma_{b}=1.13 \sqrt{f_{c}^{\prime}} \cdot \frac{1}{k_{1} k_{4}}\left(\frac{L_{f}}{d_{b}}\right)\left(\frac{C}{d_{b}}\right) \quad(C S A 2000)
\end{gathered}
$$

where $\alpha$ is modification factor which considered as 1.0 for test specimen's condition. $C$ indicates the value of concrete cover thickness in mm. The compressive strength $\left(f_{c}^{\prime}\right)$ of SFRSCC reported in Table 1. $C_{\max }$ is the maximum horizontal distance from the bar to concrete surface which equals to $69 \mathrm{~mm}$ for position of the GFRP bars in the cross-section of the experimental pullout (Mazaheripour et al. 2012a). $k_{1}$ and $k_{4}$ in Eq. (83) are bar location and bar surface factors respectively. The former equals to 1.0 for the installation of the GFRP bars in the test specimens and the later defines as a ration between the bond strength of FRP bars to that steel bars with the same diameter, but not greater than 1.0. Here, $k_{4}$ is also considered as 1.0. The Eq. (82) given by the fib is recommended for steel bars, however, this equation is also recommended for FRP bars as internal reinforcement for concrete (fib Bulletin 40, 2007). Note that the confinement effect provided by the transverse reinforcement was neglected in the above equations since no stirrup was applied to the test specimens.

In general the recommendations included in ACI, JSCE, fib and CSA do not predict the experiments, particularly for the case of the lower concrete cover $\left(C / d_{b}=1.25\right)$. It can be concluded that these formulations might not be straightforwardly used for the types of GFRP bar and SFRSCC that studied in this paper.

Based on the obtained results, for deformed GFRP bar, the minimum bond lengths required to reach the $\sigma_{b u}(1350 \mathrm{MPa}$ reported by supplier) are around $38.5 d_{b}$ and $30 d_{b}$ for $C / d_{b}$ equals to 1.25 and 2.5 , respectively. These values for smooth GFRP bar (with $\sigma_{b u}$ of around $1000 \mathrm{MPa}$ specified by the supplier) are $26.5 d_{b}$ and $20 d_{b}$. It is worth noticing that the maximum tensile stress obtained in the test for smooth bar were close to $1000 \mathrm{MPa}$ in case of $20 d_{b}$ bond length and $30 \mathrm{~mm}$ 
concrete cover; however, no rupture was reported in the bar. That means $\sigma_{b u}$ would be greater than the value reported by the manufacturer.

\section{Conclusion}

A theoretical bond model was developed to calibrate the parameters which define a multi-linear bond shear stress-slip relationship $(\tau-\delta)$ able to estimate the bond behavior between SFRSCC and GFRP. The model involved data from the experimental tests, and using an analytical-numerical algorithm to solve the governing equation on bond phenomenon of the longitudinal bars. The proposed algorithm showed good accuracy comparing with the experimental result of bending pullout tests obtaining the distribution of the bond shear stress and slip over the bond transfer length.

Due to the complexity of taking concrete deformation in the second-order differential equations, the relative slip $(\delta)$ was assumed to be equal to bar's elongation resulting that the local $\tau-\delta$ is dependent on the bond length. When the bond length is increased, the pullout force and consequently the force transferred to the surrounding concrete increases and lead to increase the amount of concrete damages over the interface which is normally formed as some inclined cracks over the embedded bar to concrete. A "material" versus "structural" bond-slip property was introduced. A local bond-slip law is a material property only when it is derived from pullout tests where the deformation and damage of the concrete surrounding the embedment FRP bar is marginal compared to the deformation of the FRP bar. This law can be used as the slip component of the constitutive law of an interface finite element, and a robust and reliable model should be adopted for modeling the behavior of the surrounding concrete up to its collapse. In the remaining cases the bond-slip relationship is a structural property.

The bond strength, which was theoretically obtained from the proposed model, was utilized to determine the development length of the GFRP bars at the ultimate limit state failed by tensile rupture in the bar. The values obtained by the model for the types of GFRP bars and concrete considered in this study showed a large discrepancy with the values recommended by the guideline of ACI committee 440 (American Concrete Institute ACI 2006), Japan Society of Civil Engineers (JSCE, 1997), CEB-FIB Model Code 2010 and Canadian Standards Association (CSA, 2000). That means, the recommendations by these guidelines may not be straightforwardly used for the reinforcing system adopted in this study.

\section{Acknowledgment}

This work is supported by FEDER funds through the Operational Programme for Competitiveness Factors - COMPETE and National Funds through FCT - Portuguese Foundation for Science and Technology under the project PTDC/ECM/105700/2008 - "DURCOST - Innovation in reinforcing systems for sustainable pre-fabricated structures of higher durability and enhanced structural performance". 


\section{References}

American Concrete Institute (ACI). (2006). "Guide for the design and construction of structural concrete reinforced with FRP bars.” ACI 440.1R-06, Detroit.

Baena, M., Torres L., Turon, A., Barris C. (2009). "Experimental study of bond behavior between concrete and FRP bars using a pull-out test.” Composite Part: B, 40(8), 784-797.

Barris, C., Torres, L., Turon, A., Baena, M., Catalan, A. (2009). “An experimental study of the flexural behaviour of GFRP RC beams and comparison with prediction models" Composite Structures 91(3), 286-295.

Bianco, V., Barros, J. A. O., Monti, G. (2009). "Bond Model of NSM-FRP Strips in the Context of the Strengthening of RC Beams.” Journal of Structural Engineering, 135(6), 619-631.

CEB-FIB (2010), “CEB-FIB Model Code 2010 - Final draft”, Thomas Thelford, Lausanne, Switzerland.

CEB-FIB (2007). "FRP reinforcement in RC structures” Bulletin No. 40, fib Task Group 9.3, Lausanne, Switzerland.

Choi, D. U., Chun, S. C., Ha, S. S., (2012), "Bond strength of glass fibre-reinforced polymer bars in unconfined concrete.” Engineering Structures 34, 303-313.

Cosenza, E., Manfredi, G., and Realfonzo, R. (1997) “'Behavior and modeling of bond of FRP rebars to concrete.’ Journal of Composites for Construction, 1(2), 40-51.

CSA. (2000). “Canadian Highway Bridge Design Code” CSA-S6-06, Canadian Standards Association, Toronto, Canada.

Eligehausen, R., Popov, E. P., and Bertero, V. V. (1983). "Local bond stress-slip relationships of deformed bars under generalized excitations." Rep. No. 83/23, Environmental Engineering Research Council, University of California, Berkeley, Calif.

Focacci, F., Nanni, A., Bakis, C. E. (2000). "Local bond-slip relationship for FRP reinforcement in concrete." Journal of Composites for Construction, 4(1), 24-31. 
Gravina, R. J., Smith, S. T. (2008) "Flexural behaviour of indeterminate concrete beams reinforced with FRP bars" Engineering Structures 30(9), 2370-2380.

Hao Q., Wang Y., He Z., Ou J. (2009). “Bond strength of glass fiber reinforced polymer ribbed rebars in normal strength concrete." Construction and Building materials, 23(2), 865-871.

Harajli, M., Abouniaj, M. (2010). "Bond Performance of GFRP Bars in Tension: Experimental Evaluation and Assessment of ACI 440 Guidelines.” Journal of Composites for Construction,14(6), 659-668.

He, Z., Tian, G. (2011). "Reliability-based bond design for GFRP-reinforced concrete." Materials and Structures 44, $1477-1489$.

JSCE. (1997). "Recommendation for Design and Construction of Concrete Structures using Continuous Fiber Reinforcing Materials" Concrete Engineering Series 23, Japan Society of Civil Engineers, Tokyo, Japan.

Li, F., Zhao, Q. L., Chen, H. S., Wang, J. Q., Duan, J. H. (2010). "Prediction of tensile capacity based on cohesive zone model of bond anchorage for fiber-reinforced polymer tendon." Composite Structures, 92(10), 2400-2405.

Malvar, L. J. (1995). “Tensile and bond properties of GFRP reinforcing bars.” ACI Journal of Materials, 92(3), 2762985.

Masmoudi, R., Masmoudi, A. Quezdou, M. B., Daoud, A. (2011). "Long-term bond performance of GFRP bars in concrete under temperature ranging from $20^{\circ} \mathrm{C}$ to $80^{\circ} \mathrm{C}$." Construction and Building Materials, 25(2), 486-493.

Mazaheripour, H., Barros, J., Sena-Cruz, J., Pepe, M., Martinelli, E. (2012a). "Experimental study on bond performance of GFRP bars in self-compacting steel fiber reinforced concrete.” Composite Structures, 25, 202-212.

Mazaheripour, H., Barros, J., Pepe, M., Giliberti, A., Martinelli, E. (2012b). "Experimental and theoretical study on bond behavior of GFRP bars in steel fiber reinforced self compacting concrete." $4^{\text {th }}$ International symposium on Bond in Concrete, Brescia, Italy. 
Pecce, M., Manfredi, G., Realfonzo R., Cosenza E. (2001). "Experimental and analytical evaluation of bond properties of GFRP bars.” Journal of Materials in Civil Engineering, 13(4), 282-290.

RILEM. Bond test for reinforcement steel 1. Beam test. 1982; TC9-RC.

RILEM TC 162-TDF (2002), “Test and design methods for steel fiber reinforced concrete.” Materials and structures, 35 , $579-582$

Russo, G., Zingone, G., Romano, F. (1990). “Analytical solution for bond-slip of reinforcing bars in R.C. joints.” Journal of Structural Engineering, 116(2), 336-355.

Sena-Cruz, J., Barros, J. (2004). "Strengthening of concrete structure with near-surface mounted CFRP laminate strips." Computers and Structures, 82(17-19), 1513-1521.

Tang, W. C., Lo, T. Y., Balendran, R. V. (2008). "Bond performance of polystyrene aggregate concrete (PAC) reinforced with glass-fibre-reinforced polymer (GFRP) bars.” Building and Environment, 43(1), 98-107.

Tastani, S. P., Pantazopolou, S. J., (2006). "Bond of GFRP Bars in Concrete: Experimental Study and Analytical Interpretation.” Journal of Composites for Construction, 10(5), 381-391.

Zhang, B., Benmokrane, B., Chennouf, A. (2000). "Prediction of tensile capacity of bond anchorages for FRP tendons." Journal of Composites for Construction, 4(2), 39-47. 


\section{NOTATION}

$A_{b}=$ area of the GFRP bar cross-section

$A_{s}=$ constant in the expression of the softening phase transfer length

$B_{s}=$ constant in the expression of the softening phase transfer length

$C=$ SFRSCC cover thickness from the bottom surface

$C_{\max }=$ maximum concrete cover thickness from the concrete surface

$C_{s}=$ constant in the expression of the softening friction transfer length

$C_{1}^{e}=$ first integration constant for the elastic phase

$C_{2}^{e}=$ second integration constant for the elastic phase

$C_{3}^{e}=$ constant value for the elastic phase

$C_{1}^{f}=$ constant value for the friction phase

$C_{2}^{f}=$ first integration constant for the friction phase

$C_{3}^{f}=$ second integration constant for the friction phase

$C_{1}^{p}=$ constant value for the plastic phase

$C_{2}^{p}=$ first integration constant for the plastic phase

$C_{3}^{p}=$ second integration constant for the plastic phase

$C_{1}^{S}=$ first integration constant for the softening phase

$C_{2}^{s}=$ second integration constant for the softening phase

$C_{3}^{s}=$ constant value for the softening phase

$E_{l b}=$ young's modulus of GFRP bar

$F \quad=\quad$ value of pullout force transferred by bond length

$F_{1}^{e}=$ maximum value of force transferred in the elastic phase in case of infinite bond length

$F^{e}=$ value of force transferred in the elastic phase in case of infinite bond length

$F^{f}=$ value of force transferred in the friction phase in case of infinite bond length

$F_{\max }=$ value of the maximum experimental pullout force transferred by $L_{f}$

$F_{2}^{p}=$ maximum value of force transferred in the plastic phase in case of infinite bond length 
$F^{p}=$ value of force transferred in the plastic phase in case of infinite bond length

$F_{3}^{s}=$ maximum value of force transferred in the softening phase in case of infinite bond length

$F^{s}=$ value of force transferred in the softening phase in case of infinite bond length

$F_{\text {res }}=$ value of the residual pullout force obtained experimentally

$J_{1}=$ constant in the governing differential equation with unknown $\delta(x)$

$L=$ span of the notched beams

$L_{f} \quad=\quad$ available finite bond length

$L_{t r 1}=$ maximum invariant value of transfer length that can undergo elastic phase

$L_{t r 2}=$ maximum invariant value of transfer length that can undergo plastic phase

$L_{t r 3}=$ maximum invariant value of transfer length that can undergo softening phase

$L_{t r}\left(\delta_{L}\right)=$ transferred bond length corresponding to whatever value of the imposed slip

$L_{t r}^{e} \quad=\quad$ transferred bond length undergoing elastic phase

$L_{t r}^{f} \quad=\quad$ transferred bond length undergoing friction phase

$L_{t r}^{s} \quad=\quad$ transferred bond length undergoing softening phase

$L_{t r}^{p} \quad=\quad$ transferred bond length undergoing plastic phase

$P \quad=\quad$ the vertical applied load in the notched beam tests

$b=$ width of the notched beams

$b_{1}=$ first constant value of fitting equation expressed $\tau_{m}-L_{f}$ relationship

$b_{2}=$ second constant value of fitting equation expressed $\tau_{m}-L_{f}$ relationship

$d_{b}=$ diameter of GFRP bars

$e \quad=$ error between experimental and theoretical pullout force-slip curves

$h_{s p}=$ height of the notched section of the beams

$i=$ number of the calculation step

$f_{c}^{\prime}=$ the compressive strength of SFRSCC

$f_{R}=$ the residual flexural tensile stress of SFRSCC

$k_{1}=$ bar location factor in equation in Eq. (67)

$k_{4}=$ bar surface factor in equation in Eq. (67) 


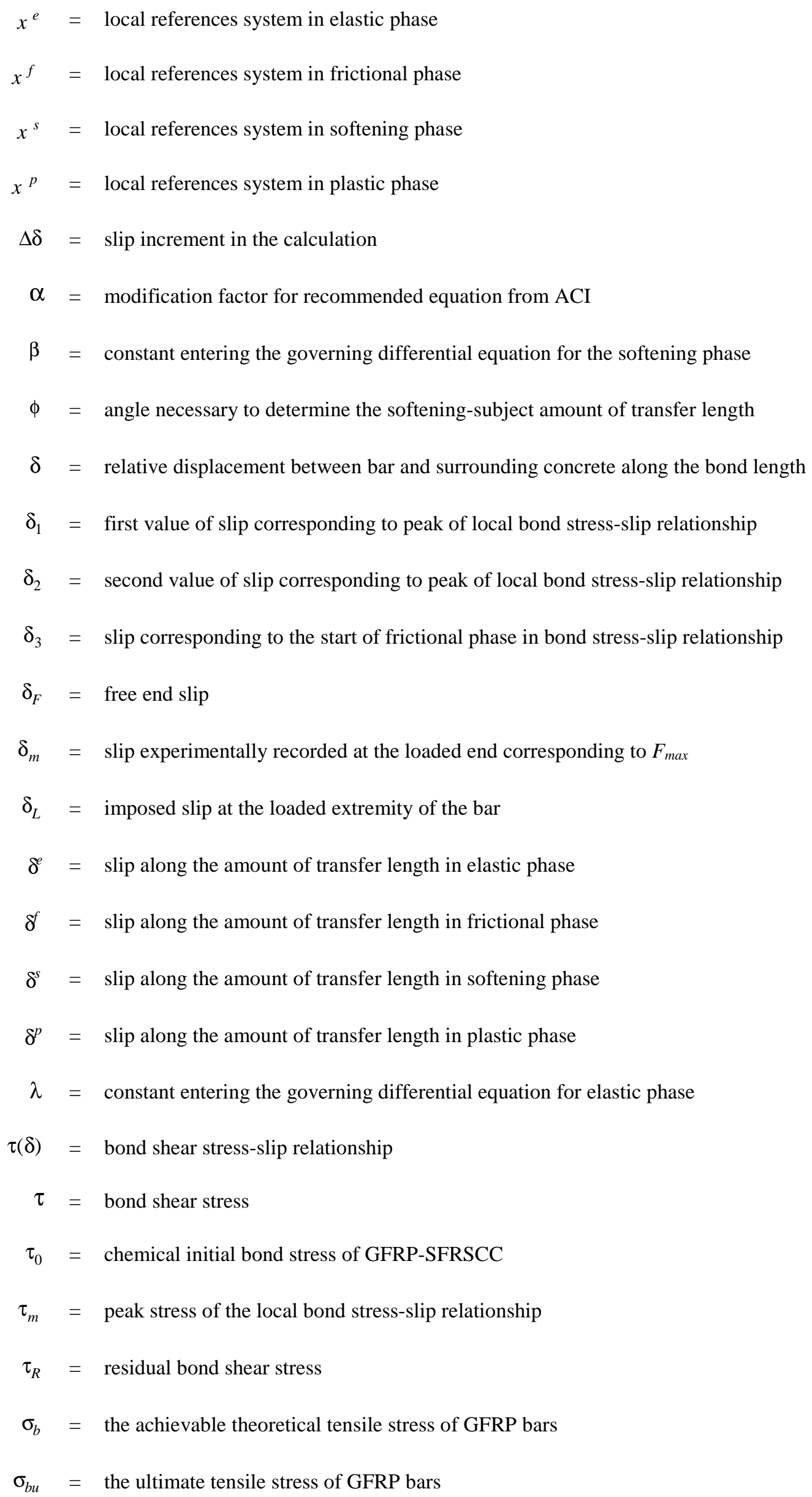


Tables

Table 1. Mechanical properties of SFRSCC

\begin{tabular}{lccc}
\hline & $\begin{array}{c}\text { Compressive } \\
\text { strength } \\
(\mathrm{MPa})\end{array}$ & $\begin{array}{c}\text { Flexural } \\
\text { tensile strength } \\
(\mathrm{MPa})\end{array}$ & $\begin{array}{c}\text { Young's modulus } \\
(\mathrm{MPa})\end{array}$ \\
\hline SFRSCC & $63.68^{2}$ & 6.48 & $30360^{3}$ \\
$(\mathrm{CoV})$ & $(5.51 \%)$ & $(17.49 \%)$ & $(15.48 \%)$ \\
\hline${ }^{1}$ Equal to Limit of Proportionality & according to CEB-FIB MC2010 \\
$(\mathrm{CMOD}=0.05 \mathrm{~mm})$ & & \\
${ }^{2}$ Mean value of 15 specimens & & \\
${ }^{3}$ Mean value of 3 specimens
\end{tabular}

Table 2. Relevant experimental results and values of the parameters of the bond model obtained from the inverse analysis

\begin{tabular}{|c|c|c|c|c|c|c|c|c|c|c|c|}
\hline \multirow[b]{2}{*}{$\boldsymbol{L}_{f}$} & \multicolumn{4}{|c|}{ Experimental results } & \multicolumn{7}{|c|}{ The results from the bond model } \\
\hline & & $\begin{array}{l}\mathrm{F}_{\max } \\
(\mathrm{kN})\end{array}$ & $\begin{array}{c}\delta_{m} \\
(\mathrm{~mm})\end{array}$ & $\begin{array}{c}\mathrm{F}_{\text {res }} \\
(\mathrm{kN})\end{array}$ & $\tau_{0}$ & $\begin{array}{c}\tau_{m} \\
(\mathrm{MPa})\end{array}$ & & & $\underset{(\mathrm{mm})}{\delta_{2}}$ & $\begin{array}{c}\tau_{R /} \tau_{m} \\
(\%)\end{array}$ & $\begin{array}{l}e \\
(\%)\end{array}$ \\
\hline \multicolumn{12}{|c|}{ Deformed GFRP bar, $12 \mathrm{~mm}$ diameter } \\
\hline \multirow[t]{2}{*}{$5 d_{b}$} & $\mathrm{C} 15$ & 44.76 & 0.33 & 17.64 & 1.0 & 18.1 & 7.6 & 0.09 & 0.152 .30 & 41.5 & 0.87 \\
\hline & $\mathrm{C} 30$ & 57.49 & 0.29 & 19.75 & 1.0 & 23.2 & 14.8 & 0.07 & 0.191 .50 & 64.4 & 0.57 \\
\hline \multirow[t]{2}{*}{$10 d_{b}$} & C15: & 70.62 & 0.84 & 31.59 & 1.0 & 14.3 & 6.8 & 0.09 & $\begin{array}{lll}0.50 & 5.0\end{array}$ & 46.6 & 0.63 \\
\hline & $\mathrm{C} 30$ & 89.54 & 1.34 & 40.99 & 1.0 & 18.3 & 8.7 & 0.15 & $0.70 \quad 5.2$ & 47.4 & 0.01 \\
\hline \multirow[t]{2}{*}{$20 d_{b}$} & C15: & 121.81 & 2.56 & 50.22 & 1.0 & 12.5 & 5.1 & 0.12 & 1.807 .0 & 39.0 & 0.48 \\
\hline & $\mathrm{C} 30$ & 146.23 & 3.00 & 61.63 & 1.0 & 14.9 & 5.9 & 0.11 & 1.208 .6 & 33.9 & 2.63 \\
\hline \multicolumn{12}{|c|}{ Smooth GFRP bar, $12 \mathrm{~mm}$ diameter } \\
\hline \multirow[t]{2}{*}{$5 d_{b}$} & $\mathrm{C} 15$ & 42.06 & 0.47 & 18.63 & 1.0 & 18.0 & 8.3 & 0.10 & $0.16 \quad 1.1$ & 47.2 & 0.80 \\
\hline & C30: & 50.815 & 0.44 & 38.73 & 1.0 & 21.9 & 13.1 & 0.09 & $0.15 \quad 1.1$ & 60.5 & 0.97 \\
\hline \multirow[t]{2}{*}{$10 d_{b}$} & $\mathrm{C} 15$ & 62.92 & 0.81 & 28.08 & 1.0 & 14.0 & 6.0 & 0.10 & $\begin{array}{ll}0.35 & 1.9\end{array}$ & 42.7 & 1.09 \\
\hline & $\mathrm{C} 30$ & 76.64 & 1.50 & 42.06 & 1.0 & 16.5 & 9.0 & 0.10 & $0.55 \quad 2.0$ & 50.5 & 2.60 \\
\hline \multirow[t]{2}{*}{$20 d_{b}$} & C15: & 98.74 & 2.04 & 54.47 & 1.0 & 12.2 & 5.8 & 0.10 & $\begin{array}{ll}0.5 & 2.0\end{array}$ & 44.7 & 1.23 \\
\hline & $\mathrm{C} 30$ & 106.24 & 2.36 & 70.06 & 1.0 & 13.2 & 7.6 & 0.10 & $\begin{array}{ll}0.7 & 2.0\end{array}$ & 50.7 & 1.20 \\
\hline
\end{tabular}

Table 3. Values of parameters adopted for parametric study *

\begin{tabular}{|c|c|c|c|c|c|c|c|c|}
\hline Stage & $\begin{array}{c}d_{b} \\
\mathrm{~mm}\end{array}$ & $\begin{array}{c}\tau_{0} \\
\mathrm{MPa}\end{array}$ & $\begin{array}{c}\tau_{m} \\
\mathrm{MPa}\end{array}$ & $\begin{array}{c}\tau_{R} \\
\mathrm{MPa}\end{array}$ & $\begin{array}{c}\delta_{1} \\
\mathrm{~mm}\end{array}$ & $\begin{array}{c}\delta_{2} \\
\mathrm{~mm}\end{array}$ & $\begin{array}{c}\delta_{3} \quad E_{l b} \\
\mathrm{mmGPa}\end{array}$ & $\begin{array}{c}L_{f} \\
\mathrm{~mm}\end{array}$ \\
\hline Study 1 & 12 & 1 & $5-25$ & $0.5 \tau_{m}$ & 0.1 & 0.2 & 60 & $5,10,20,25,30 d_{b}$ \\
\hline Study 2 & 12 & 1 & $14,16,18$ & $0.5 \tau_{m}$ & 0.1 & 0.2 & 60 & $5 d_{b}-30 d_{b}$ \\
\hline Study 3 & 12 & 1 & 18 & $0.5 \tau_{m}$ & $.01-0.5$ & $1,2,3 \delta_{1}$ & 60 & $5,10,20 d_{b}$ \\
\hline Study 4 & 12 & 1 & 18 & $0.5 \tau_{m}$ & 0.1 & $0.1-2$ & 60 & $5,10,20 d_{b}$ \\
\hline Study 5 & 12 & 1 & 18 & $0.5 \tau_{m}$ & 0.1 & $0.1,0.3,0.5 \delta_{3}$ & 1-5 60 & $5,10,20 d_{b}$ \\
\hline Study 6 & 12 & 1 & 18 & $0.5 \tau_{m}$ & 0.1 & 0.2 & $330-65$ & $5,10,20 d_{b}$ \\
\hline
\end{tabular}


Table 4. The parameters adopted in the model to obtain the maximum tensile stress for whatever value of $L_{f}$

\begin{tabular}{|c|c|c|c|c|c|c|c|c|c|c|}
\hline \multirow{2}{*}{ GFRP } & & \multirow{2}{*}{$\begin{array}{c}d_{b} \\
(\mathrm{~mm})\end{array}$} & \multirow{2}{*}{$\begin{array}{c}E_{l b} \\
(\mathrm{GPa})\end{array}$} & \multirow{2}{*}{$\delta_{1}$} & \multirow{2}{*}{$\begin{array}{c}\delta_{2} \\
(\mathrm{~mm})\end{array}$} & \multirow{2}{*}{$\delta_{3}$} & \multirow{2}{*}{$\begin{array}{c}\tau_{0} \\
(\mathrm{MPa})\end{array}$} & \multicolumn{2}{|c|}{$\tau_{m}{ }^{*}$} & \multirow{2}{*}{$\begin{array}{c}\tau_{R} \\
(\mathrm{MPa})\end{array}$} \\
\hline & & & & & & & & $b_{1}$ & $b_{2}$ & \\
\hline \multirow[t]{2}{*}{ Deformed bar } & C15: & 13.08 & 56.0 & 0.10 & 0.50 & 3.0 & 1.0 & $\begin{array}{r}55.41 \\
\left(\mathrm{R}^{2}=0\right.\end{array}$ & $\begin{array}{l}-0.276 \\
.96)^{* * *}\end{array}$ & $0.5 \tau_{m}$ \\
\hline & C30: & 13.08 & 56.0 & 0.10 & 0.50 & 3.0 & 1.0 & $\begin{array}{r}86.70 \\
\left(\mathrm{R}^{2}=0\right.\end{array}$ & $\begin{array}{l}-0.323 \\
0.99)\end{array}$ & $0.5 \tau_{m}$ \\
\hline \multirow[t]{2}{*}{ Smooth bar } & C15: & 12.36 & 49.0 & 0.10 & 0.50 & 2.0 & 1.0 & $\begin{array}{r}58.61 \\
\left(\mathrm{R}^{2}=0\right.\end{array}$ & $\begin{array}{l}-0.291 \\
0.95)\end{array}$ & $0.5 \tau_{m}$ \\
\hline & C30: & 12.36 & 49.0 & 0.10 & 0.50 & 2.0 & 1.0 & $\begin{array}{r}100.09 \\
\left(\mathrm{R}^{2}=0\right.\end{array}$ & $\begin{array}{l}-0.373 \\
0.99)\end{array}$ & $0.5 \tau_{m}$ \\
\hline
\end{tabular}

* Obtained from Eq. (63); ${ }^{* *}$ Coefficient of determination; 


\section{Figures}

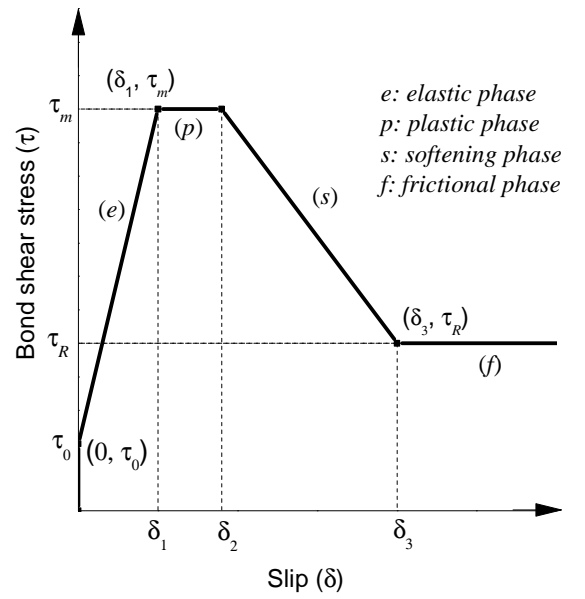

Fig. 1. The local bond shear stress-slip relationship

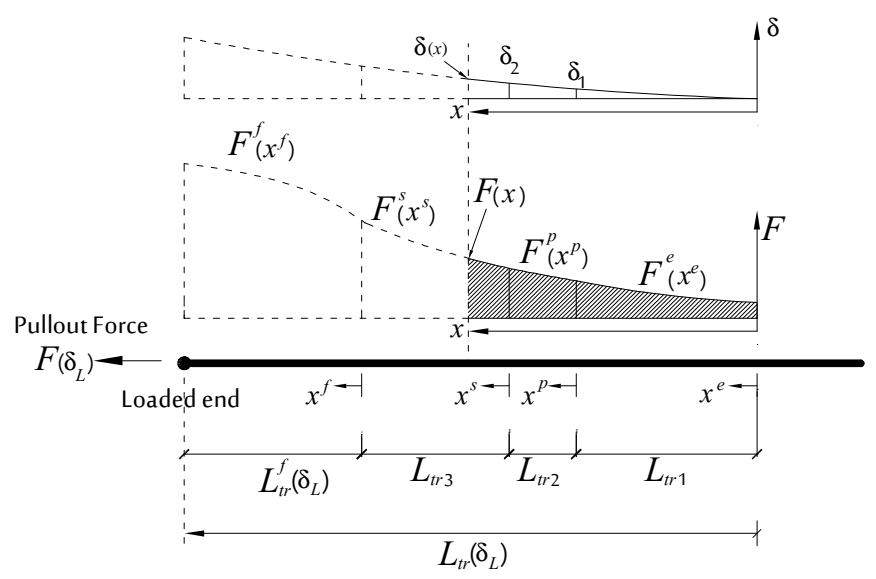

Fig. 2. Debonding process in case of infinite bond length: pullout force, $F(x)$, slip distribution, $\delta(x)$, the required transfer bond length, $L_{t r}\left(\delta_{L}\right)$, and definition of local reference systems

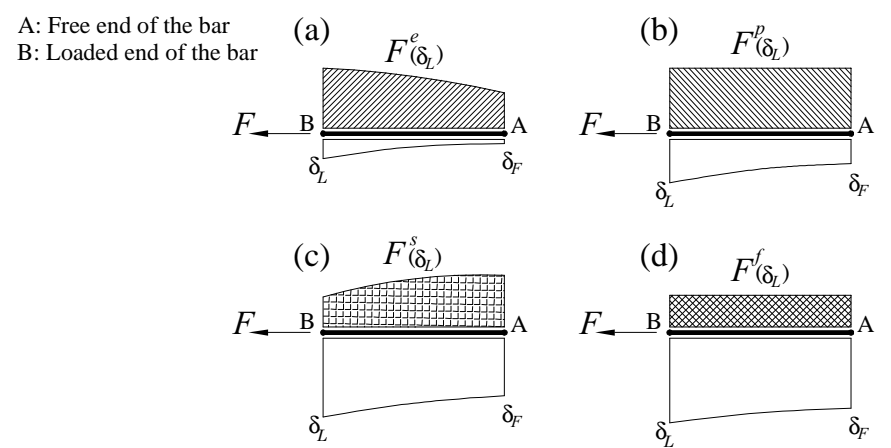

Fig. 3. The configurations for $\delta(x)$ and $F(x)$ over $L_{f}$ when one bond phase is acting: (a) Fully Elastic, (b) Fully Plastic,

(c) Fully Softening, (d) Fully Frictional 
$(\mathrm{i}-1)^{\text {th }}$ converged step

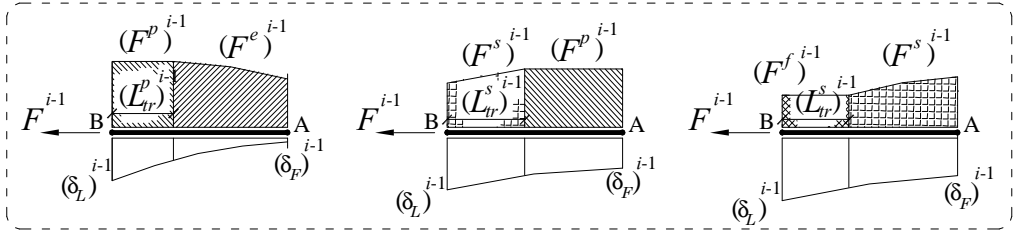

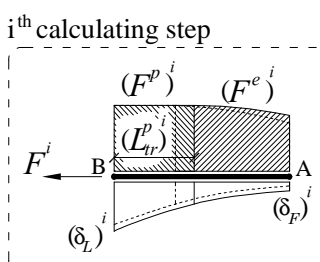

(a)

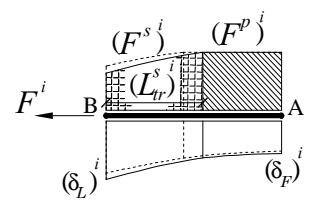

(b)

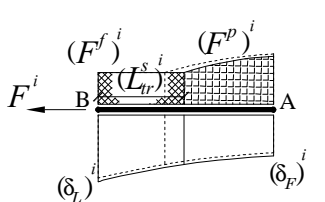

(c)

Fig. 4. The configurations for $\delta(x)$ and $F(x)$ over $L_{f}$ when two bond phases are acting (a) Elastic-Plastic, (b) PlasticSoftening, (c) Softening-Frictional

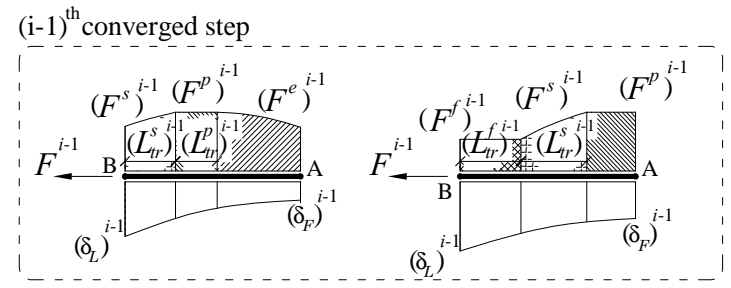

$\mathrm{i}^{\text {th }}$ calculating step

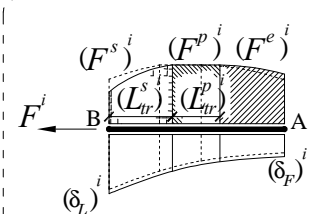

(a)

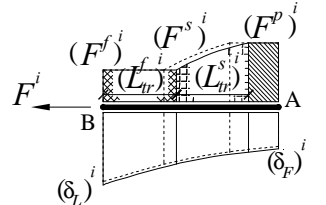

(b)

Fig. 5. The configurations for $\delta(x)$ and $F(x)$ over $L_{f}$ when three bond phases are acting: (a) Elastic-Plastic-Softening (b) Plastic-Softening-Frictional

$(\mathrm{i}-1)^{\text {th }}$ converged step

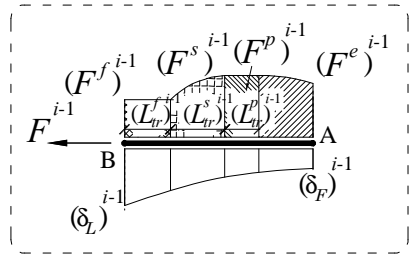

$\mathrm{i}^{\text {th }}$ calculating step

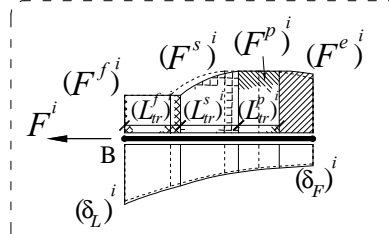

Fig. 6. The configurations for $\delta(x)$ and $F(x)$ over $L_{f}$ when four bond phases are acting: Elastic-Plastic-Softening-

Frictional 


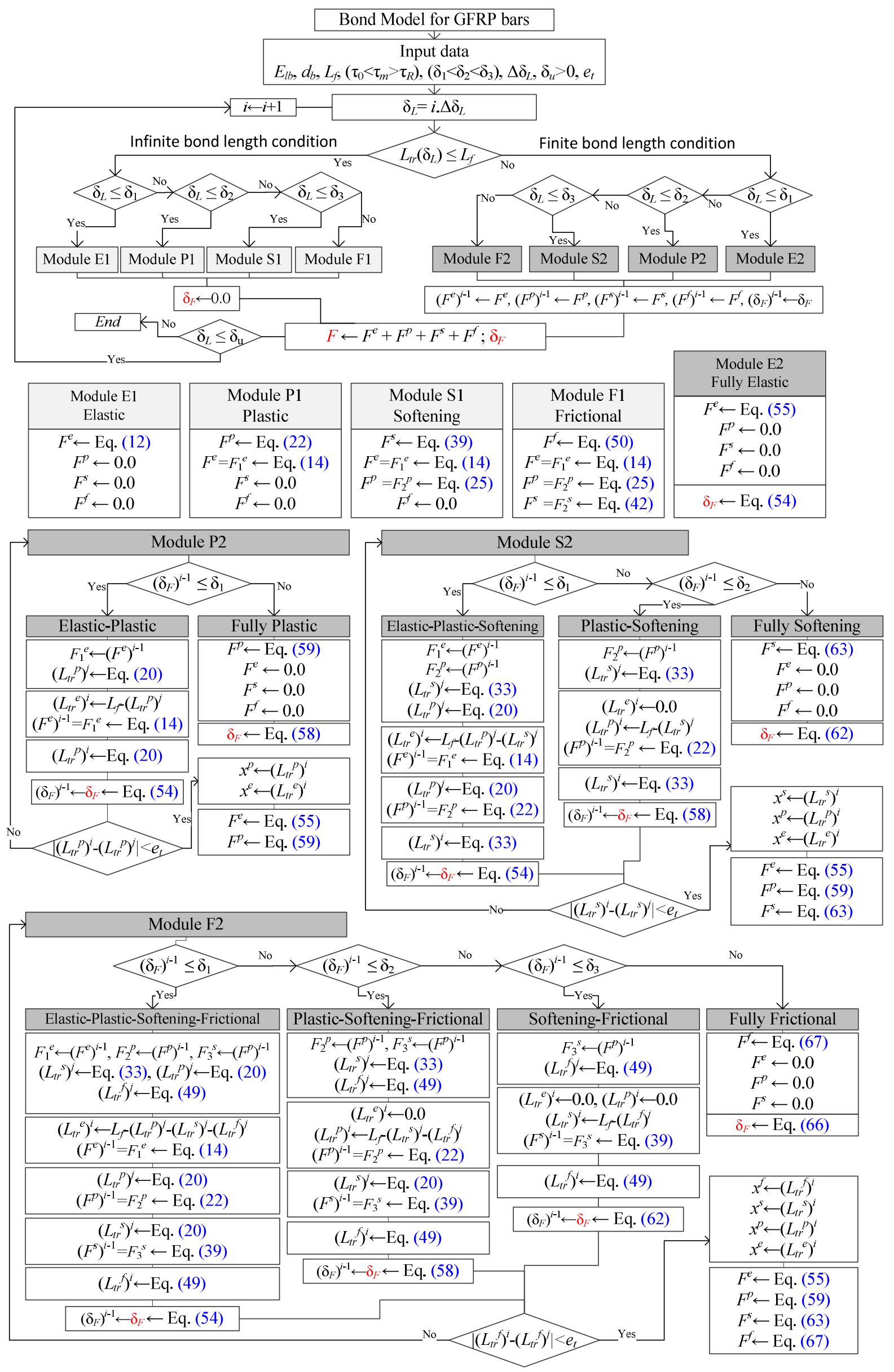

Fig. 7. Flowchart of the proposed bond model 


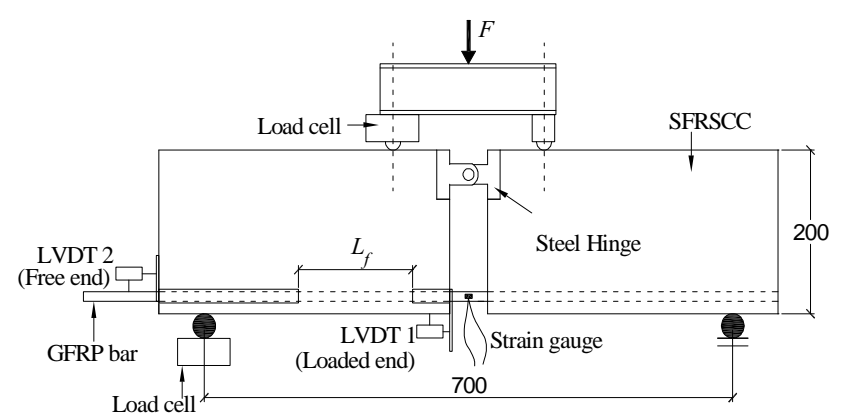

Fig. 8. The pullout bending test setup (Mazaheripour et al., 2012a) 


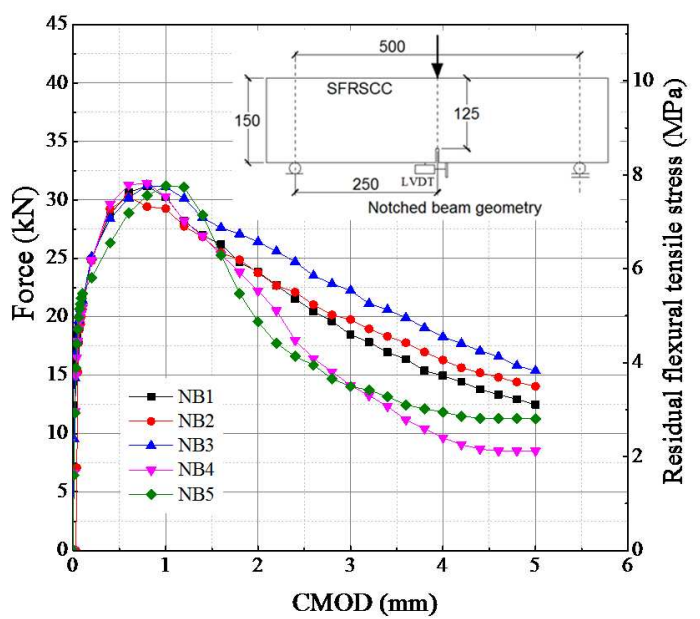

Fig. 9. The results of the notched beam bending tests carried out to characterize the SFRSCC 


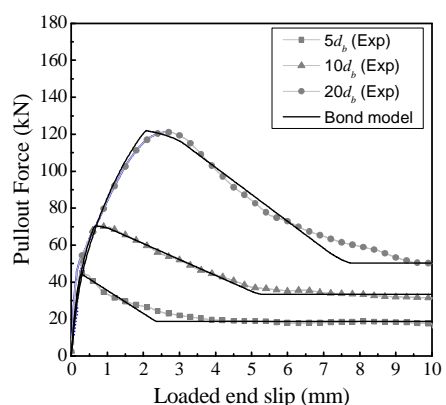

(a)

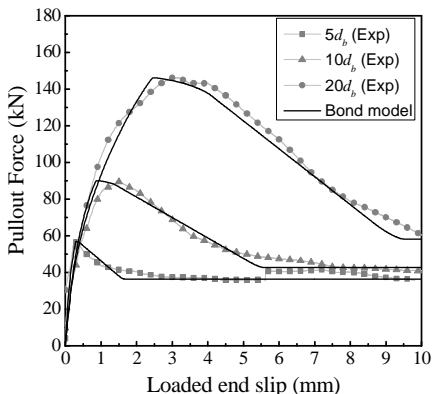

(b)

Fig. 10. The comparison between theoretical and experimental pullout force versus loaded end slip for deformed GFRP bar: (a) $15 \mathrm{~mm}$ and (b) $30 \mathrm{~mm}$ concrete cover

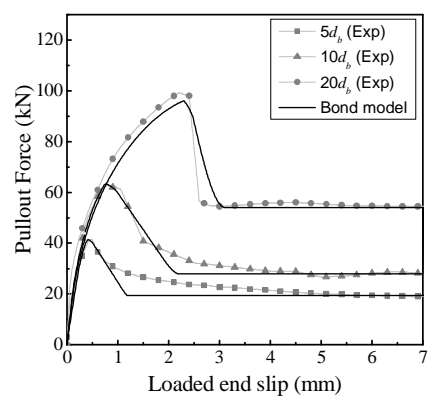

(a)

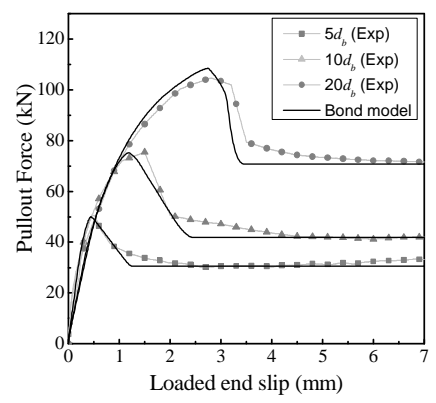

(b)

Fig. 11. The comparison between theoretical and experimental pullout force versus loaded end slip for smooth GFRP bar: (a) $15 \mathrm{~mm}$ and (b) $30 \mathrm{~mm}$ concrete cover

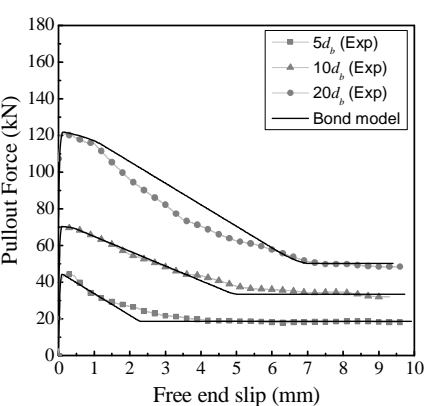

(a)

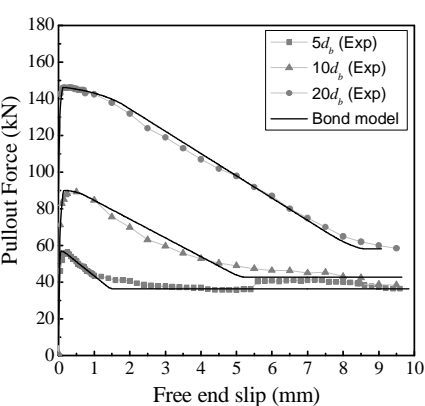

(b)

Fig. 12. The comparison between theoretical and experimental pullout force versus free end slip for deformed GFRP bar: (a) $15 \mathrm{~mm}$ and (b) $30 \mathrm{~mm}$ concrete cover 


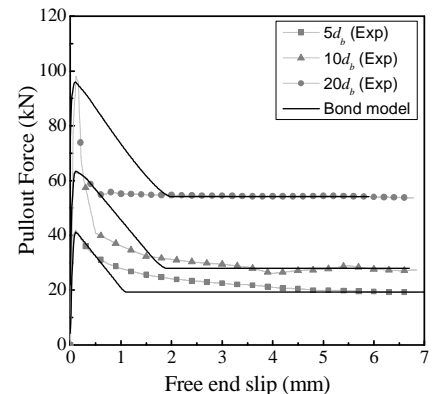

(a)

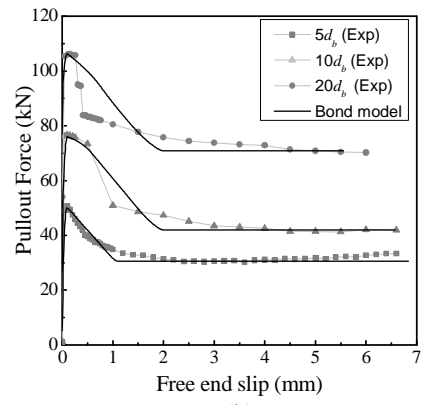

(b)

Fig. 13. The comparison between theoretical and experimental pullout force versus free end slip for smooth GFRP bar:

(a) $15 \mathrm{~mm}$ and (b) $30 \mathrm{~mm}$ concrete cover

\section{(7)}

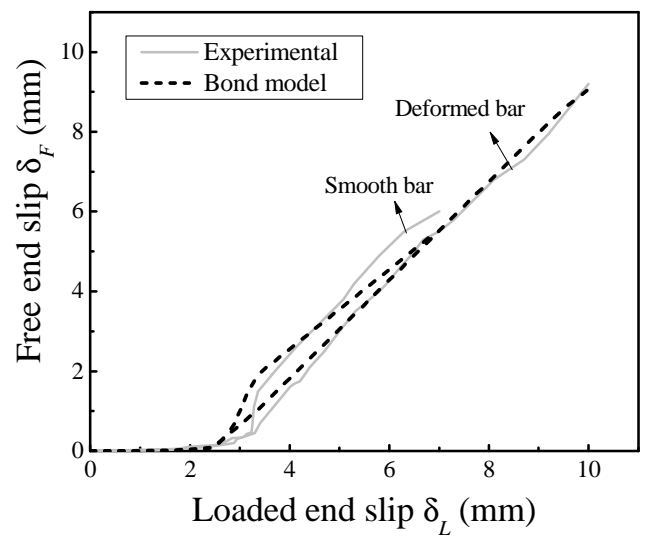

Fig. 14. The relationship between loaded and free end slip $\left(\delta_{L^{-}} \delta_{F}\right)$ for specimen with $L_{f}=20 d_{b}$
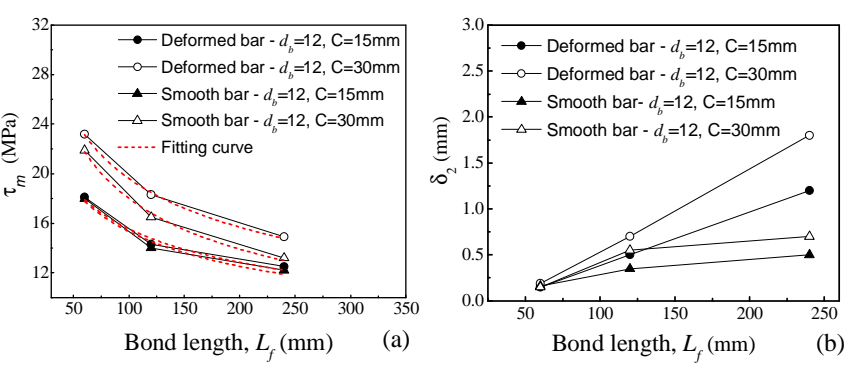

Fig. 15. (a) the analytical bond strength $\left(\tau_{m}\right)$ and (b) corresponding slip at the end of the plastic phase $\left(\delta_{2}\right)$ versus bond length $\left(L_{f}\right)$ 

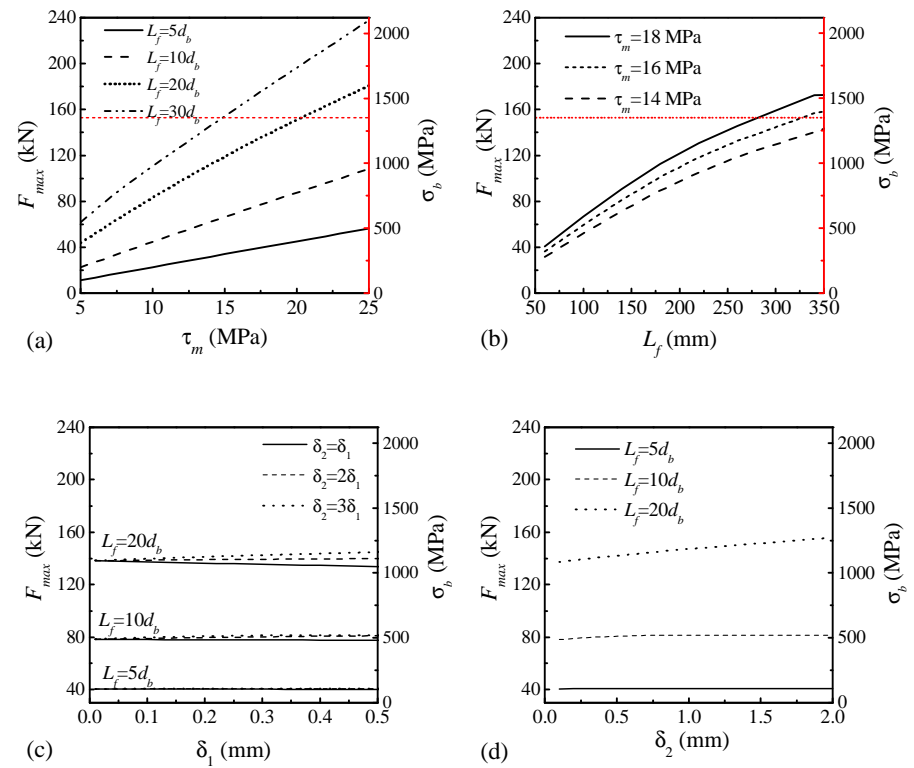

(d)
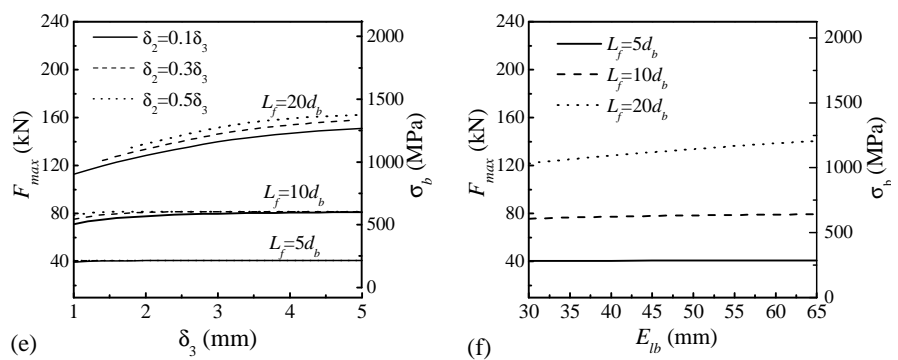

\section{9}

30

31

32

Fig. 16. Appraisal of influence of (a) the maximum bond stress; (b) bond length; (c) slip at the end of elastic phase $\left(\delta_{1}\right)$; (d) slip at the end of plastic phase $\left(\delta_{3}\right)$; (e) slip at the end of softening phase; (f) GFRP' Young's modulus on maximum force transferred by bond length

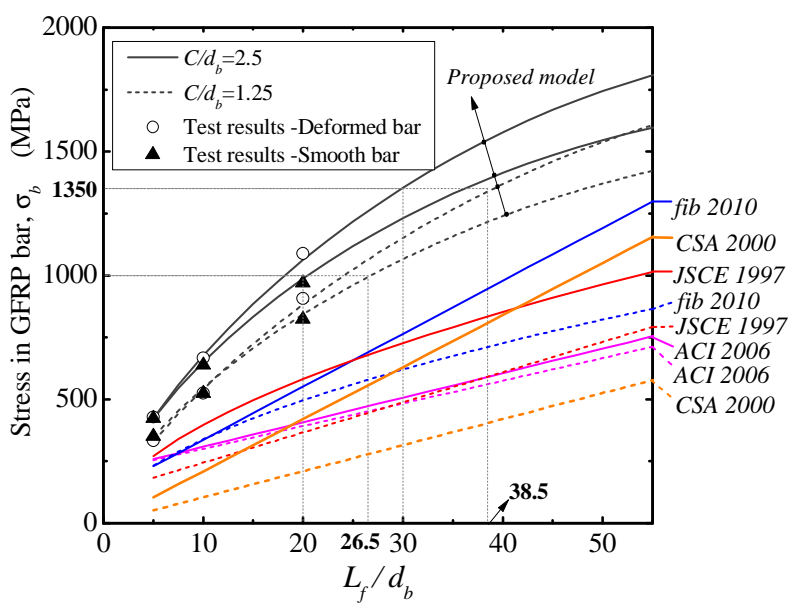

Fig. 17. The tensile stress of GFRP bars versus $L_{f} / d_{b}$ 